\title{
The Cross-Correlations between Foreign Flows in Chinese A-Share Markets and Uncertainties in Home Markets
}

\author{
Tao Bing $\mathbb{D}^{1}{ }^{1}$ Fei Hu $\mathbb{D}^{2},{ }^{2}$ and Hongkun $\mathrm{Ma} \mathbb{D}^{3,4}$ \\ ${ }^{1}$ School of Finance, Capital University of Economics and Business, Beijing 100070, China \\ ${ }^{2}$ Chinese Academy of Macroeconomic Research, Beijing 100038, China \\ ${ }^{3}$ Zhuhai Huafa Investment Holdings Group Co. Ltd., Hengqin 519000, China \\ ${ }^{4}$ School of Business, Sun Yat-sen University, Guangzhou 510275, China \\ Correspondence should be addressed to Hongkun Ma; mahongkun1212@163.com
}

Received 7 October 2021; Accepted 2 November 2021; Published 19 November 2021

Academic Editor: Dehua Shen

Copyright (c) 2021 Tao Bing et al. This is an open access article distributed under the Creative Commons Attribution License, which permits unrestricted use, distribution, and reproduction in any medium, provided the original work is properly cited.

\begin{abstract}
This paper investigates the cross-correlations between the foreign flows in A-share market and the uncertainties of market, economy, and policy in home markets, namely, the VIX index and the US EPU index. By employing the cross-correlation statistics and MF-DCCA method, we find the existence of the cross-correlations between the foreign flows and the VIX index, the foreign flows, and the US EPU index from qualitative and quantitative perspectives, respectively. For the cross-correlation between the foreign flows and VIX, small fluctuations are persistent, while large fluctuations are antipersistent. In contrast, the cross-correlation between the foreign flows and US EPU is antipersistent and steady. These results are robust by dividing the foreign flows into two parts in Shenzhen and Shanghai stock exchanges, respectively, and by shortening the periods to after the implementation of Shenzhen-Hong Kong Stock Connect.
\end{abstract}

\section{Introduction}

Since China opened its door to the world in 1978, the financial liberalization has been increased (https://business.cornell. edu/hub/2020/05/11/chinas-financial-liberalization/). And the Keynote Speech by Xi Jinping, the president of the People's Republic of China, at the Opening of the Boao Forum for Asia Annual Conference 2018 initiates the new round of the opening-up of Chinese financial market. After that, the limited amounts of QFII and RQFII have been relaxed, the Shanghai-London Stock Connect Program has been implemented, and the foreign equity caps in the banking, securities, and insurance industries have also been raised. As a result, we can see that the foreign investment has been increasing in recent years (see the news from the Global Time: https://www.globaltimes.cn/page/202108/1231158. shtml.), and the holding of foreign investors in A-share market continuously increases (see Figure 1). Therefore, it is important to be clear about the factors affecting the foreign flows in A-share market.
In fact, this problem has been discussed since the early 1990s. Calvo et al. [1] and Fernandez-Arias [2] firstly introduce the framework of push and pull factors to analyze the factors that influence the international capital flows (the pull factors relate to the host economic forces that attract foreign capital, such as high host interest rates, stable political environment, and high growth potential). The push factors relate to the external or global or home forces that push international capital flows to the host markets, such as the low interest rates, high international political and market uncertainty, low potential growth, and the portfolio diversification. The later literature studies, such as Taylor and Sarno [3], Agénor [4], Chuhan et al. [5], Forbes and Warnock [6], Fratzscher [7], and Fuertes et al. [8], have further discussed this problem. See the review of Koepke Koepke [9] for more details. In recent years, the outbreaks of the global financial crisis, the catastrophic risk (such as the 9/11, China's 2008 earthquake, and Japan's 2011 earthquake), and the global public safety events (such as the Ebola and COVID-19) cause great uncertainties of market, economy, and policy. These 


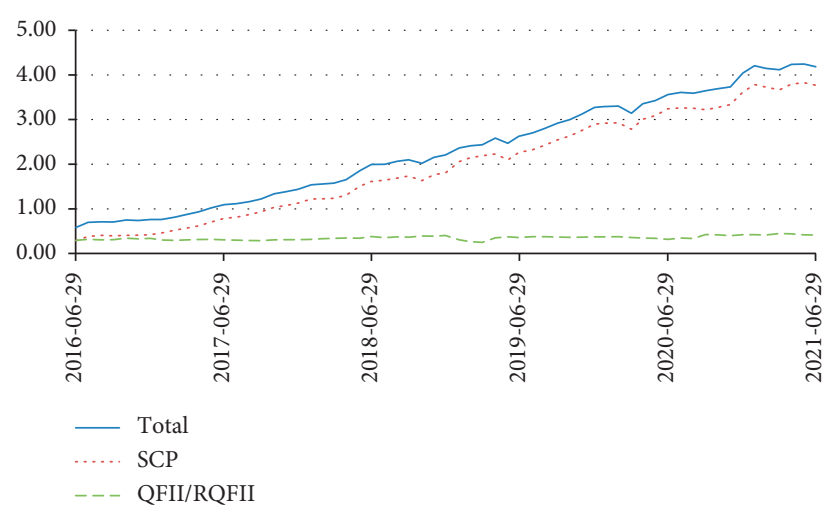

FIGURE 1: The holding share of foreign investors in A-share market from 29 June 2016 to 29 June 2021. The SCP refers to the foreign flows via the Stock Connect Program; QFII and RQFII refer to the Qualified Foreign Institutional Investors and RMB Qualified Foreign Institutional Investors, respectively.

uncertainties change the market sentiment and investors' expectations of economy and the fundamental value of assets and influence investors' trading behavior and their flows. And these effects are more pronounced for the trading behavior and flows of foreign investors in emerging markets. However, the results are not consistent. On the one hand, Borensztein and Gelos [10] report that foreign institutional investors are prone-panic due to their information disadvantage in emerging countries. Omay and Iren [11] find that foreign investors exhibit herding behavior, and the foreign flows tend to be unstable and prone to flee the Malaysian stock market during the 1997 Asian Crisis and the 2008 Global Financial Crisis. Hood et al. [12] find significant positive feedback and momentum trading patterns of foreign investors, namely, net foreign outflows, during Japan's 2011 earthquake. On the other hand, Gerlach and Yook [13] show that foreign investors deviate from the general positive feedback trading strategy and increase their holding of Korean stocks during the 13 North Korean military attacks from 1999 to 2010. And Bing and $\mathrm{Ma}$ [14] find significant negative feedback trading of foreign investors in A-share market during the COVID-19 crisis. Besides, Choe et al. [15] show that the strong positive feedback trading of foreign investors before Korea's financial crisis disappears during the crisis. Similar results are reported during the Asian crisis in Indonesia [16].

Therefore, it is necessary to investigate the relationships between flows and uncertainties. The existing literature mainly studies their linear relationship and rarely discusses the nonlinear relationship. However, many financial variables and their relations display properties of multifractality (see the review of Jiang et al. [17] for more details. Dai et al. [18] and Zhao and Dai [19] also discuss the multifractality of China EPU and US EPU). This paper will investigate the cross-correlations between the foreign flows in A-share markets and the uncertainties of market, economics, and policy in home market using the MF-DCCA approach proposed by Zhou [20] (the MF-DCCA approach has been widely used to study the nonlinear cross-correlation in financial markets, such as the cross-correlation between stock returns and news (Zhang et al. [21], Zhang et al. [22], and
Zhang et al. [23]), online sentiment and market returns [24], EPU and exchange rate [25], exchange rate and market anxiety [26], China EPU and US EPU [19], carbon market price and EPU [27], cryptocurrency uncertainty indices and EPU [28], investors' attention and index futures [29], returnvolume relationship of bitcoin market [30], online searches and bitcoin market [31], and online sentiment proxies [32]). The uncertainty of market is measured by the market panic index, namely, the VIX index (the VIX index has been widely used in the previous literature $[26,33])$. And the uncertainty of economy and policy can be measured by the economic policy uncertainty (EPU) index developed by Baker et al. [34].

Our main findings are as follows: first, there are significant power-law relationship and a long-term crosscorrelation between the foreign flows and VIX index, the foreign flows, and US EPU index. The Renyi exponent confirms the results. Second, the cross-correlation Hurst exponents show that cross-correlation between the foreign flows and US EPU is antipersistent and steady, while the cross-correlation between the foreign flows and VIX is antipersistent only when the fluctuations are large. When the fluctuations are small, the cross-correlation is persistent. In addition, the multifractal spectrum analysis shows that the strength of the cross-correlation between the foreign flows and VIX is larger than that between the foreign flows and US EPU. And the above results are robust by further analysis using the separate foreign flows, namely, the flows via Shanghai-Hong Kong Stock Connect Program and Shenzhen-Hong Kong Stock Connect Program, and the foreign flows after the implementation of Shenzhen-Hong Kong Stock Connect.

This paper contributes to the existing literature by verifying the cross-correlation between the foreign flows and VIX index, the foreign flows, and US EPU. To the best of our knowledge, this is the first paper to investigate the nonlinear relationships between the foreign flows in emerging markets and the uncertainty in home markets, which enriches linear analytical framework for the drivers of foreign flows to emerging markets. These results would be helpful for policy makers to forestall potential imported financial risks.

The remainder of the paper is organized as follows. In Section 2, we describe the methodology in detail. Section 3 describes the data. Section 4 shows the empirical results. For robustness, we shorten the sample period and replace the overall foreign flows with the separate flows in Section 5 . Finally, Section 6 concludes the paper.

\section{Methodology}

In this section, the MF-DCCA approach used to explore the cross-correlation between the foreign flows and VIX index, the foreign flows, and the US EPU index will be described.

2.1. Cross-Correlation Analysis. To statistically examine the cross-correlation between the series, the cross-correlation statistic methodology proposed by Podobnik and Stanley [35] will be employed. The cross-correlation analysis $Q_{c c}(m)$ 
of the two series $\left\{x_{i}\right\}$ and $\left\{y_{i}\right\}$ is defined as shown in the following equation:

$$
Q_{c c}(m)=N^{2} \sum_{i=1}^{m} \frac{C_{i}^{2}}{N-i}
$$

where $m$ is the degree of freedom, $N$ is the length of the series $\left\{x_{i}\right\}$ and $\left\{y_{i}\right\}$, and $C_{i}$ is the cross-correlation function and can be calculated as follows:

$$
C_{i}=\frac{\sum_{j=i+1}^{N} x_{j} y_{j-i}}{\sqrt{\sum_{j=1}^{N} x_{j}^{2} \sum_{j=1}^{N} y_{j}^{2}}} .
$$

$Q_{c c}(m)$ is approximately $\chi^{2}(m)$ distributed with $m$ degrees of freedom. The null hypothesis of the cross-correlation is that the cross-correlations are not significantly different from zero. Therefore, if $Q_{c c}(m)$ is greater than the critical value of $\chi^{2}(m)$, there is a cross-correlation between the two series. Otherwise, there is no cross-correlation.

2.2. MF-DCCA. Consider two series $\left\{x_{i}\right\}$ and $\left\{y_{i}\right\}$, where $i=$ $(1,2, \ldots, N)$ and $N$ is the length. The MF-DCCA approach could be constructed by the following steps:

Step 1. Construct the profiles $\left\{X_{i}\right\}$ and $\left\{Y_{i}\right\}$ of the two series, respectively.

$$
\begin{aligned}
& X_{i}=\sum_{k=1}^{i}\left(x_{i}-\bar{x}\right), \\
& Y_{i}=\sum_{k=1}^{i}\left(y_{i}-\bar{y}\right),
\end{aligned}
$$

where $\bar{x}$ and $\bar{y}$ are the mean value of the two series, respectively.

Step 2. Divide the profiles into $N_{s}=\operatorname{int}(N / s)$ nonoverlapping segments, where int denotes floor rounding function, and $s$ is the length of the segments. As $N$ is not always a multiple of $s$, a small part of the profile with length $\left(N-N_{s} * s\right)$ will be left. To make the most of the information contained in the data, the same procedure is repeated from the end of the profiles. Therefore, there are $2 \mathrm{Ns}$ segments.

Step 3. Calculate the detrended covariance of every segment. First, we use the ordinary least squares (OLS) to obtain the local trend of every segment. Then, we calculate the detrended covariance. For the segment $v=1,2, \ldots, N_{s}$, the detrended covariance could be obtained by the following equation:

$$
F^{2}(v, s)=\frac{1}{s} \sum_{j=1}^{s}\left(X_{(v-1) s+j}-\widetilde{X}_{(v-1) s+j}\right)\left(Y_{(v-1) s+j}-\widetilde{Y}_{(v-1) s+j}\right) .
$$

For the segment $v=N_{s}+1, N_{s}+2, \ldots 2 N_{s}$, the detrended covariance is presented in the following equation:

$$
F^{2}(v, s)=\frac{1}{s} \sum_{j=1}^{s}\left(X_{N-\left(v-N_{s}\right) s+j}-\tilde{X}_{N-\left(v-N_{s}\right) s+j}\right)\left(Y_{N-\left(v-N_{s}\right) s+j}-\tilde{Y}_{N-\left(v-N_{s}\right) s+j}\right)
$$

where $\tilde{X}_{v}$ and $\tilde{Y}_{v}$ are the local trend of segment $v$.

Step 4. Calculate the $q$ th-order fluctuation function by averaging all the detrended segment variances. For $q \neq 0$,

$$
F_{q}(s)=\left[\frac{1}{2 N_{s}} \sum_{v=1}^{2 N_{s}} F^{2}(v, s)^{q / 2}\right]^{1 / q}
$$

For $q=0$, the fluctuation function could be obtained by L'Hospital's rule:

$$
F_{0}(s)=\exp \left[\frac{1}{4 N_{s}} \sum_{v=1}^{2 N_{s}} \ln F^{2}(v, s)\right]
$$

Step 5. Analyze the multifractal features. If the two series are long-term cross-correlated, there is a powerlaw relationship between $F_{q}(s)$ and the scale $s$ :

$$
F_{q}(s) \propto s^{H_{x y}(q)},
$$

where $H_{x y}(q)$ could be obtained by the log-log plots of $F_{q}(s)$ verse $s$ though the OLS estimation. $H_{x y}(q)$ is the generalized Hurst exponent. If $H_{x y}(q)$ varies with $q$, the cross-correlation between the two series has multifractal features. If $H_{x y}(q)$ is greater than 0.5 , the cross-correlation between the two series is persistent and positive. If $H_{x y}(q)$ is less than 0.5 , the crosscorrelation between them is antipersistent and negative. If $H_{x y}(q)$ is equal to 0.5 , there is no significant consistent cross-correlation between them. In particular, when $q$ is equal to $2, H_{x y}(2)$ is the standard Hurst index.

Furthermore, we could get the relationship between the multifractal scaling Renyi exponent $\tau_{x y}(q)$ (provided by Shadkhoo and Jafari [36] and $q$ by the following equation:

$$
\tau_{x y}(q)=\mathrm{qH}_{x y}(q)-1
$$


If $\tau_{x y}(q)$ and $q$ are linear, the cross-correlation between them is monofractal. Otherwise, their cross-correlation is multifractal. And we can get the multifractal spectrum $f_{x y}(\alpha)$ through the Legendre transformation:

$$
\begin{aligned}
\alpha & =H_{x y}(q)+\mathrm{qH}_{x y}^{\prime}(q), \\
f_{x y}(\alpha) & =q\left(\alpha-H_{x y}(q)\right)+1,
\end{aligned}
$$

where $H_{x y}^{\prime}(q)$ is the derivative of $H_{x y}(q)$. And $\alpha$ is the singularity strength, which describes the strength of singularity spectrum. The value of the multifractal spectrum, $f_{x y}(\alpha)$, shows the fractal dimension of $\alpha$.

According to Yuan et al. [37], the multifractal intensity could be measured by $\Delta H=H_{\max }(q)-H_{\min }(q)$, namely, the width of the multifractal spectrum. The higher the value of $\Delta H$, the stronger multifractality and the greater corresponding market risk, and vice versa.

\section{Data}

In the A-share market, foreign investors trade mainly though the Qualified Foreign Institutional Investors (QFII) scheme and the Stock Connect Program (SCP). Compared to the QFII scheme, the SCP has advantages in transaction cost, transaction settlement, and the trading qualification authentication. Therefore, even though the QFII scheme was implemented as early as 2002, the SCP (the SCP includes Shanghai-Hong Kong Stock Connect and Shenzhen-Hong Kong Stock Connect, launched in 17 November 2014 and 5 December 2016, respectively.), launched in 17 November 2014, has been the preferred trading channel for foreign investors (see the holding share of foreign investors in Figure 1). Besides, there are great differences in the availability of data. The data of QFII could be only obtained by their quarterly position data, while Hong Kong Exchanges and Clearing Limited discloses the foreign investors' trading data every day. Based on the above two reasons, we select the flows though the SCP as the representative of foreign trading. The data of foreign flows could be collected from the WIND database. And we use the daily net inflows in the model (if the values is greater than zero, this indicates net inflows; otherwise, it indicates net outflows.).

We choose VIX index to measure market panic, which has been widely used in prior literature [38-41]. And the VIX index could also be collected from the WIND database. Since the foreign flow is daily net inflows, we adopt daily changes in VIX, which is similar to the prior literature $[26,33]$.

The EPU index (this index is constructed by counting the articles in 10 leading newspapers that contain the following three sets of terms: economic or economy, uncertain or uncertainty, and the government actions, such as White House, Federal Reserve, legislation, deficit, regulation, and congress. For more details, see Baker et al. [34] and the website http://www.policyuncertainty.com/index.html.), developed by Baker et al. [34], has been extensively used in the literature to measure the uncertainty of economic policy (the EPU has been extensively discussed in financial markets, such as its relationship with corporate investment [42], mergers and acquisitions [43], market returns [27], and exchange rate [25]. See the review of Al-Thaqeb and Algharabali [44] for details. Dai et al. [45] proposed a global economic policy uncertainty index to measure the economic policy uncertainty on a global scale. And this index has been used to predict crude oil futures volatility [46]. But this index is monthly frequency. We can not use it in this paper). Considering that the flows and VIX are daily data, we choose the daily EPU, namely, the US EPU index (the US EPU can be downloaded from this website: http://www. policyuncertainty.com/us_monthly.html). And we use daily changes in US EPU in this paper.

Since the SCP was launched in 17 November 2014, we choose the sample periods from 17 November 2014 to 30 May 2021. The vacant data due to China and US holidays are deleted. The descriptive statistics of the series are presented in Table 1. The Jarque-Bera tests of the three series all reject the normal distribution null hypothesis at $1 \%$ significance level.

\section{Empirical Results}

4.1. Cross-Correlation Test. We first employ the cross-correlation analysis to examine the cross-correlations between the two pairs of the series. Figure 2 shows the results of the cross-correlation statistics $Q_{c c}(m)$ with degrees of freedom $m$ ranging from 1 to $N-1$. The critical values of the $\chi^{2}(m)$ at $5 \%$ significant level are shown with red lines to make a clear comparison. We can find that most values of $Q_{c c}(m)$ for both the two pairs exceed the critical value. These results reject the null hypothesis of no cross-correlations. Therefore, there is a long-term cross-correlation between the foreign flows in A-share market and VIX and the foreign flows in A-share market and US EPU.

4.2. Multifractal Detrended Cross-Correlation Analysis. In this section, we will examine the cross-correlation between the two pairs of the series using the MF-DCCA method. Consistent with the prior research $[20,21]$, we set the scale $q$ from -10 to 10 with the step width of 1 . Figure 3 shows the $\log$-log plots of the fluctuation function $F_{q}(s)$ versus $s$ between the foreign flows in A-share market and VIX and the foreign flows in A-share market and US EPU. The results show that $F_{q}(s)$ increases with the scale $s$. And the curves show the linearity within a certain interval. Therefore, there exist a significant power-law relationship and a long-term cross-correlation between the two pairs of series.

Figure 4 describes the relationship between the generalized Hurst exponent and $q$ for the two pairs of series. The results show that the cross-correlation Hurst exponent $H_{x y}(q)$ decreases with the increase of $q$, indicating that there exists a multifractality in the cross-correlation between the foreign flows and VIX and the foreign flows and US EPU. In particular, for the series of foreign flows and VIX, when $q$ is less than $4, H_{x y}(q)$ is greater than 0.5 , and its trend is relatively steady. This indicates that the cross-correlation is persistent when the fluctuation $q$ is small. When $q \geq 4$, $H_{x y}(q)$ is less than 0.5 , indicating that the cross-correlation 
TABle 1: Descriptive statistics of net foreign flows in A-share market, the change of VIX index, and US EPU index.

\begin{tabular}{lccc}
\hline & VIX change & Net foreign flows & US EPU change \\
\hline $\mathrm{N}$ & 1511 & 1511 & 1511 \\
Mean & 0.002 & 9.208 & 0.076 \\
Median & -0.080 & 6.284 & 0.140 \\
Std. dev. & 2.119 & 34.486 & 57.822 \\
Maximum & 24.860 & 217.233 & 267.360 \\
Minimum & -17.640 & -173.842 & -282.840 \\
Skewness & 2.761 & 0.717 & 0.046 \\
Kurtosis & 35.903 & 10.308 & 6.610 \\
Jarque-Bera & $70079.860^{* * *}$ & $3491.684^{* * *}$ & $820.817^{* * *}$ \\
\hline
\end{tabular}

${ }^{* * *}$ Statistical significance at the 0.001 .
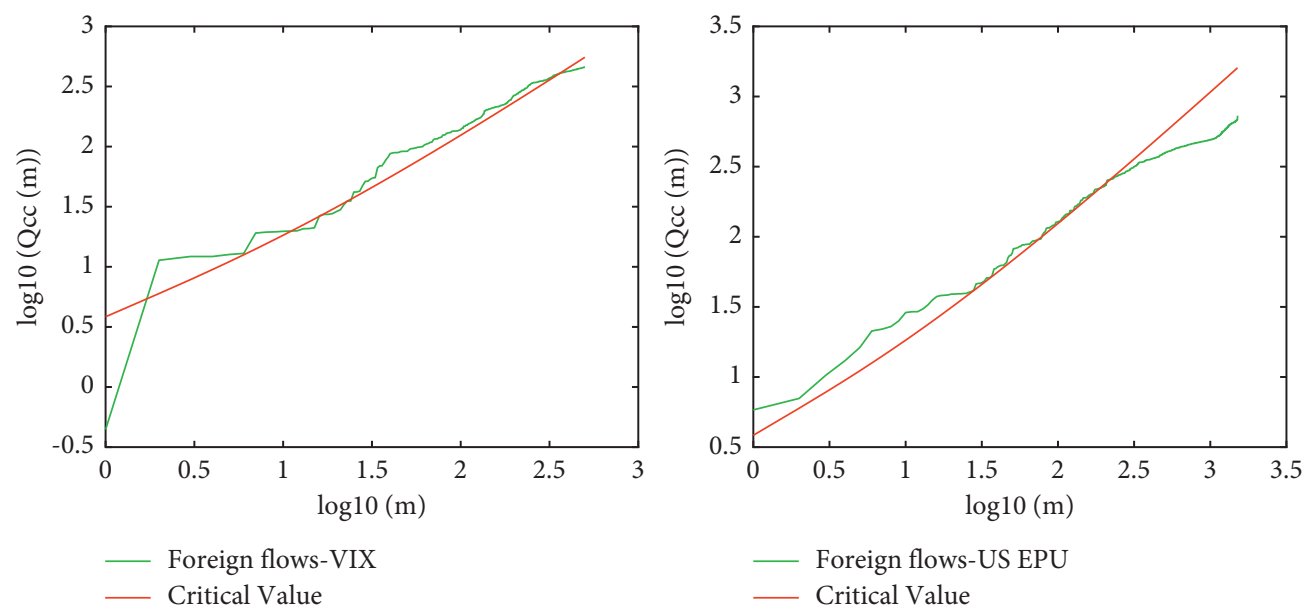

Figure 2: The cross-correlation statistics $Q_{c c}(m)$ between the foreign flows in A-share market and VIX and the foreign flows in A-share market and US EPU.
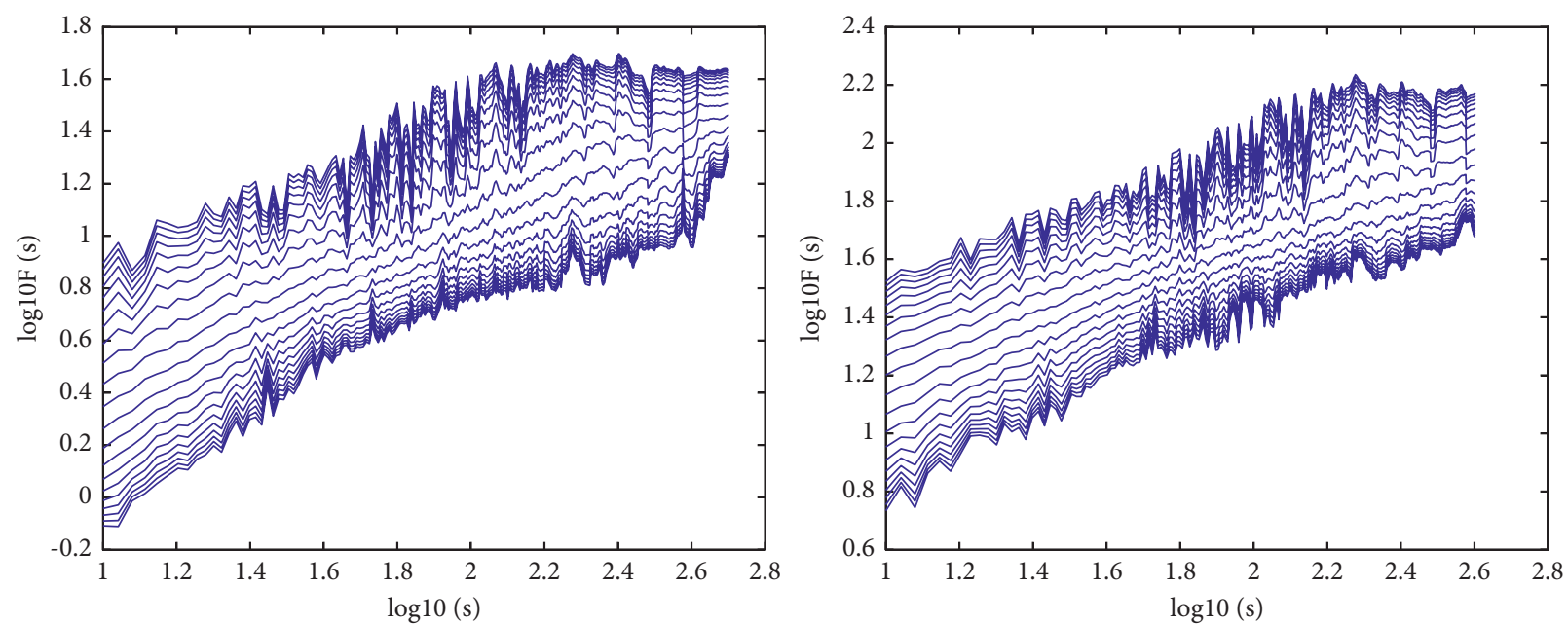

FIgURE 3: The log-log plots of $F_{q}(s)$ versus $s$ between the foreign flows in A-share market and VIX and the foreign flows in A-share market and US EPU. The order of $q$ increases from the bottom to the top.

is antipersistent. The change of the cross-correlation may be explained by the characteristics of the international financial flow. When the fluctuations are small, they are volatile at the host markets, namely, US market or global market for foreign markets. The emerging markets such as A-share market may be a haven for international capital. Therefore, foreign investors trade in A-share market. Namely, net inflows occur. However, the big fluctuations may indicate 

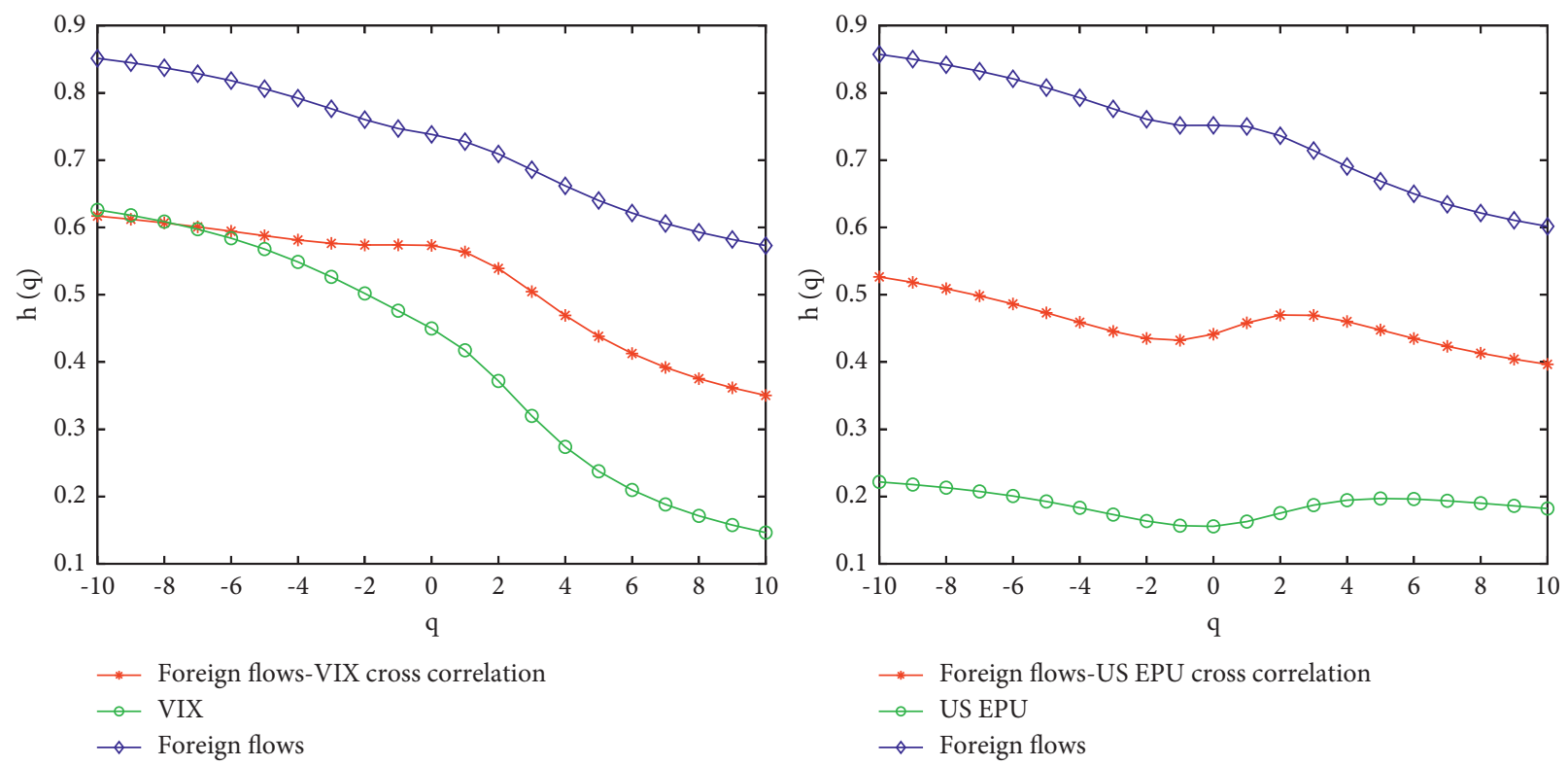

Figure 4: The generalized Hurst exponent of $H(q)$ versus $q$ for the foreign flows in A-share market and VIX and the foreign flows in A-share market and US EPU.

global risk, or the risk may spread from US market to emerging markets. Therefore, there is a net outflow of international capital. For the series of foreign flows and US EPU, the Hurst exponent $H_{x y}(q)$ is less than 0.5 when $q$ is greater than -8 , indicating that their cross-correlation is antipersistent. Compared to that between the foreign flows and VIX, the cross-correlation between the foreign flows and US EPU is more steady.

Figure 5 presents the relationship between Renyi exponent $\tau(q)$ and $q$. The results show that the cross-correlations between $\tau(q)$ and $q$ for the two pairs of series are nonlinear, confirming their multifractal cross-correlation properties.

Figure 6 shows the multifractal spectrum $f_{x y}(\alpha)$ versus $\alpha$ for two pairs of series. If the multifractal spectrum is a point, monofractality exists; otherwise, monofractality exists. We can see that all the multifractal spectrum varies significantly, confirming the cross-correlation between the foreign flows and VIX and the foreign flows and US EPU. Besides, the width of the multifractal spectrum, namely, the difference between the maximum of $\alpha$ and the minimum of $\alpha$, measures the strength of the multifractal. As shown in Figure 6, the width of the spectrum of foreign flows and VIX is larger than that of foreign flows and US EPU, indicating that the strength of the cross-correlation between the foreign flows and VIX is larger.

\section{Further Analysis}

As mentioned above, the SCP could be divided into two stages: the implementation of Shanghai-Hong Kong Stock Connect Program and Shenzhen-Hong Kong Stock Connect Program. The cross-correlations between the overall foreign flows and VIX and the overall foreign flows and US EPU have been investigated in Section 4. In this section, we will further divide the foreign flows into two parts: the foreign flows via Shanghai-Hong Kong Stock Connect Program (HGT (here, we use HGT and SGT to denote the net foreign flows via Shanghai-Hong Kong Stock Connect Program and Shenzhen-Hong Kong Stock Connect Program, respectively)) and via Shenzhen-Hong Kong Stock Connect Program (SGT). And then, we will explore the cross-correlation between the separate foreign flows and VIX index and the separate foreign flows and US EPU index. Besides, the implementation of ShenzhenHong Kong Stock Connect increases the overall foreign flows in A-share market, which may affect the above cross-correlation. Therefore, we will investigate the crosscorrelation with the overall foreign flows after the implementation of Shenzhen-Hong Kong Stock Connect. The above two analyses will further enrich our cognition about the cross-correlations between the foreign flows and VIX and foreign flows and US EPU. More importantly, these can also be a robust test for the conclusion in Section 4.

First, we show the cross-correlation analysis for the separate foreign flows via two stock exchange ((a) in Figures 7 to 10). Most values of $Q_{c c}(m)$ for all the pairs, except the HGT and US EPU, exceed the critical value, indicating a long-term cross-correlation among all the pairs. And the values of $Q_{c c}(m)$ between the HGT and US EPU are close to the critical value. The MF-DCCA analysis could give further evidence to show their cross-correlation relationship. All the $\log$-log plots of $F_{q}(s)$ versus $s((\mathrm{~b})$ in Figures 7-10) show that the fluctuation function $F_{q}(s)$ increases with $s$, indicating the significant power-law relationship and a long-term cross-correlation among the pairs of series.

And the Hurst exponent $H_{x y}(q)$ decreases with $q$ ((c) in Figures 7-10), which indicates a multifractality in the cross-correlation among all the pairs. The decreasing 

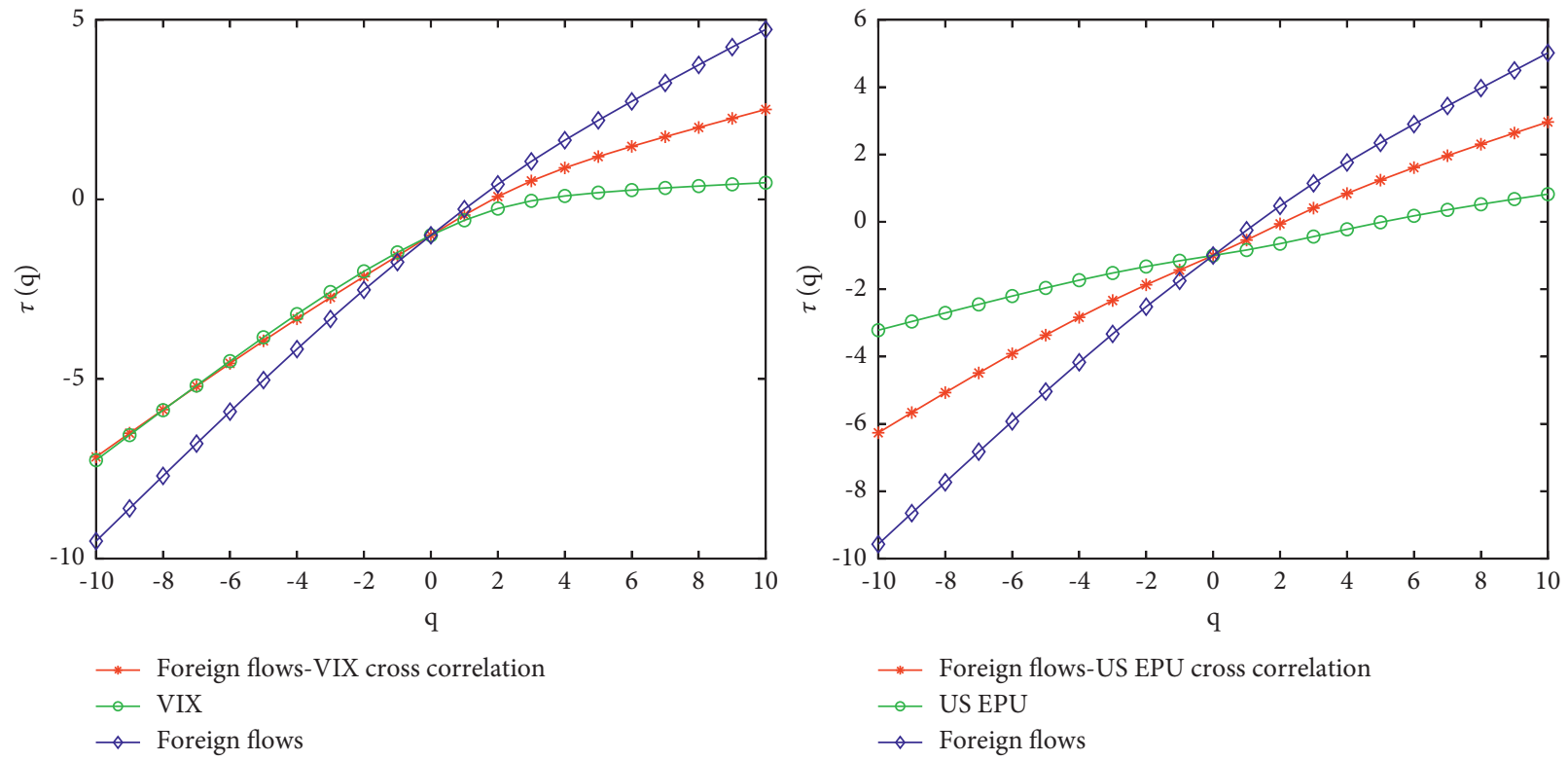

FIgURE 5: The Renyi exponent of $\tau(q)$ versus $q$ for the foreign flows in A-share market and VIX and the foreign flows in A-share market and US EPU.
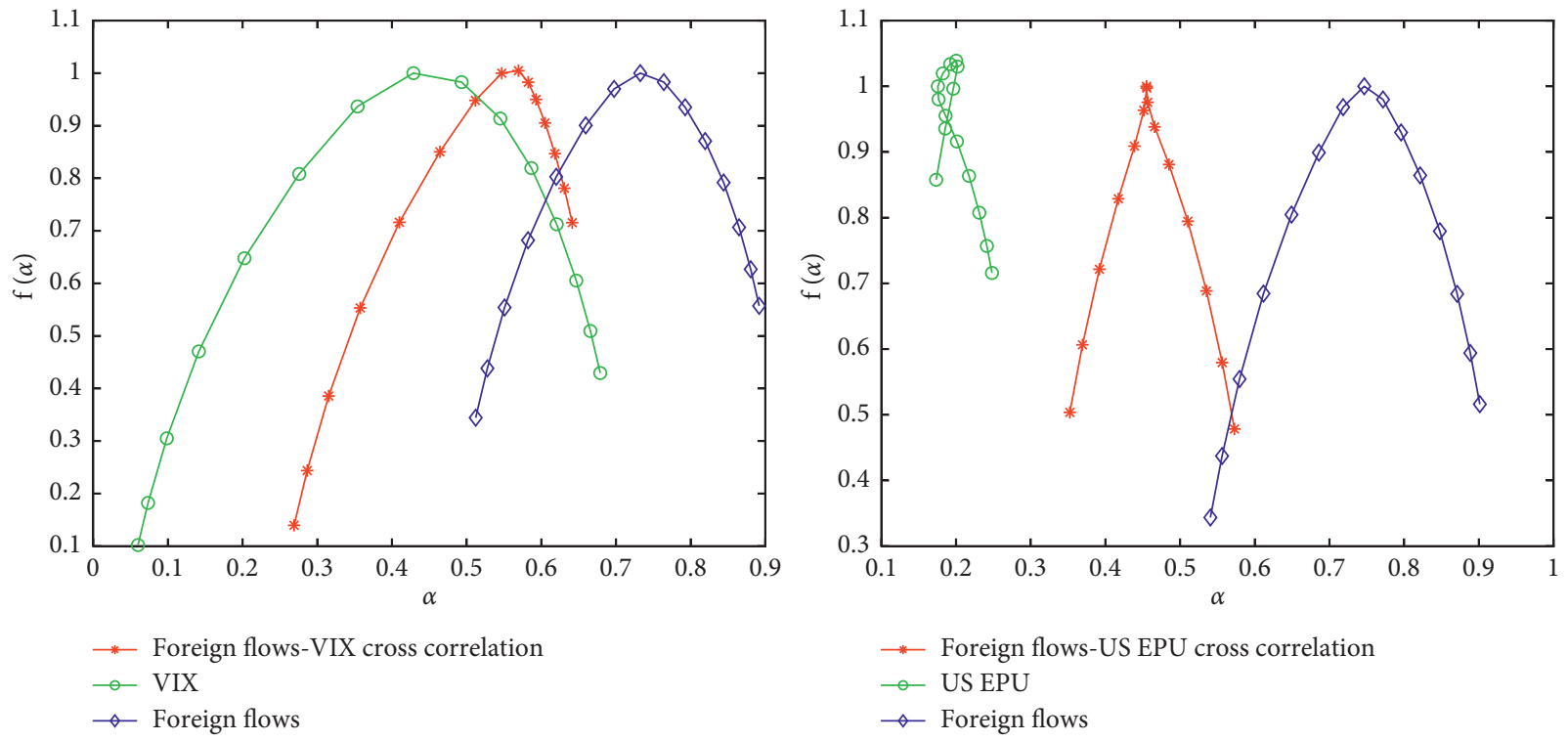

Figure 6: The multifractal spectrum $f(\alpha)$ versus $\alpha$ for the foreign flows in A-share market and VIX and the foreign flows in A-share market and US EPU.

amplitude of $H_{x y}(q)$ for HGT and VIX, and SGT and VIX is greater than that for HGT and US EPU, and SGT and US EPU. And most values of $H_{x y}(q)$ for HGT and US EPU, and SGT and US EPU are lower than 0.5. And the $H_{x y}(q)$ is more steady than that for HGT and VIX, and SGT and VIX. Besides, the values of $H_{x y}(q)$ for SGT and VIX, except $q=10$, are greater than 0.5 , indicating that the cross-correlation is persistent, while $H_{x y}(q)$ is greater than 0.5 when $q$ is less than 2 , and it is less than 0.5 when $q$ is greater than 2 . This is consistent with the results for the overall flows and VIX. All the curves of the Renyi exponent $\tau(q)$ versus $q((\mathrm{~d})$ in Figures 7-10) for four pairs of series are nonlinear, which confirm the multifractal crosscorrelation. Furthermore, the results of multifractal spectrum analysis ((e) in Figures 7-10) verify the crosscorrelation. And the strength of the cross-correlation between the foreign flows and VIX is larger than that between the foreign flows and US EPU. In conclusion, the above results are consistent with those in Section 4.

Second, we analyze the cross-correlation for the period after the implementation of Shenzhen-Hong Kong Stock Connect. Overall, the results confirm the multifractal cross-correlation between the foreign flows and VIX and the foreign flows and US EPU, which are consistent with 


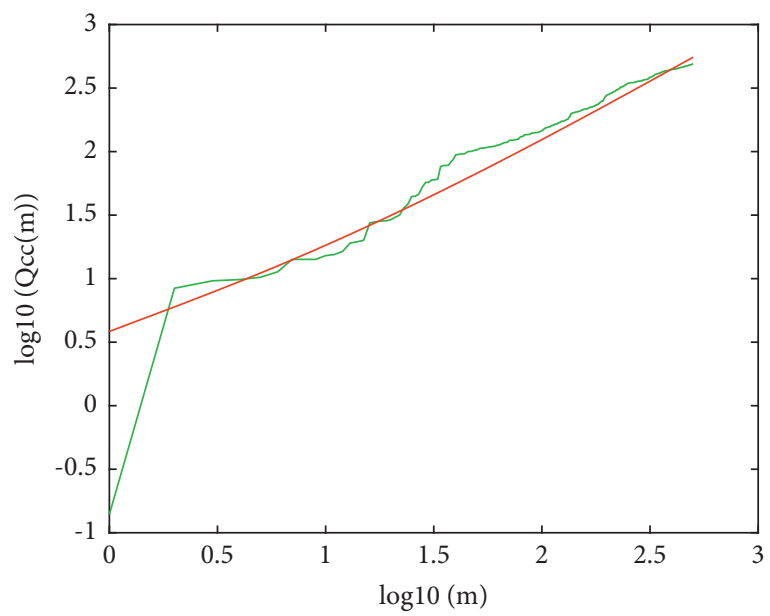

_ Foreign flows-VIX

- Critical Value

(a)

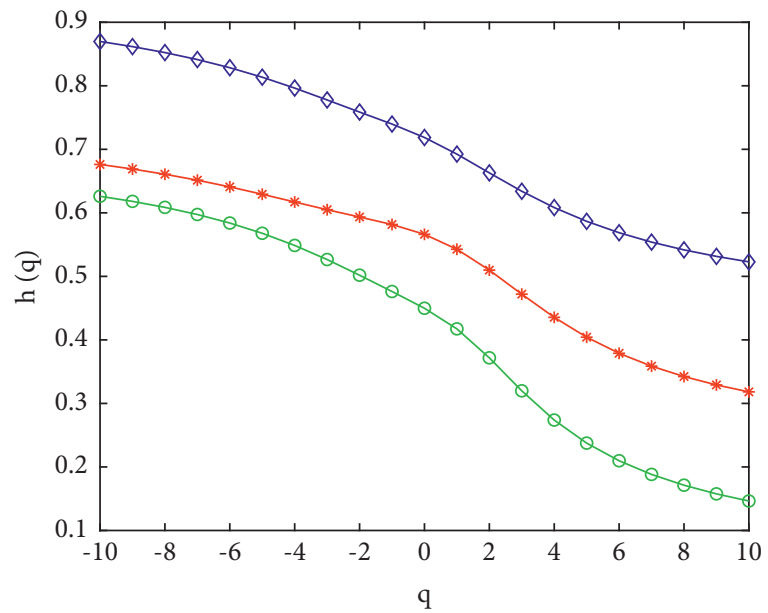

$\rightarrow$ Foreign flows-VIX cross correlation

- - VIX

$\neg$ Foreign flows

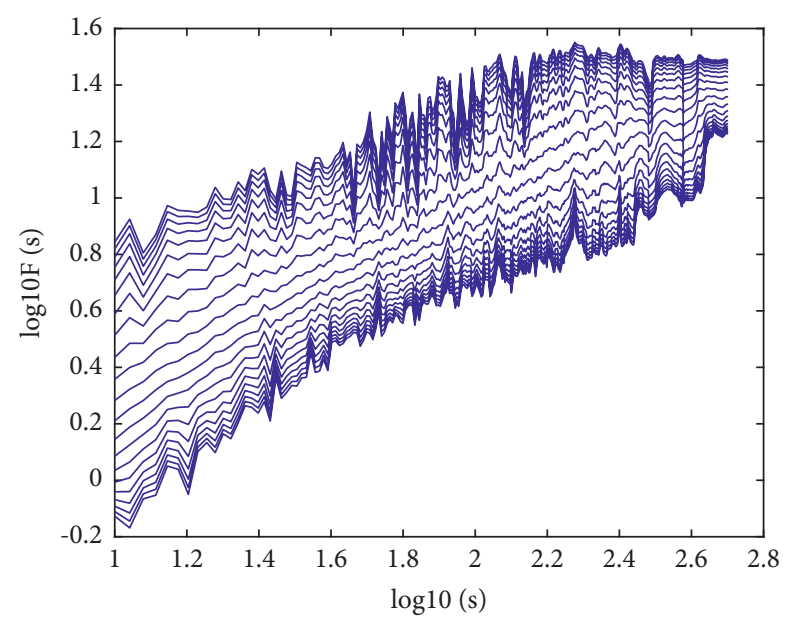

(b)

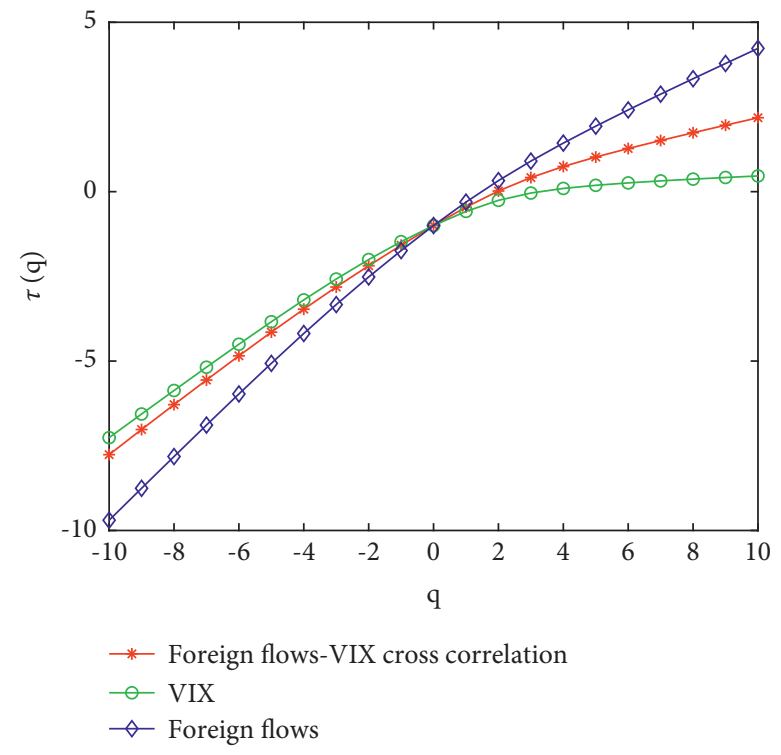

(d)

Figure 7: Continued. 


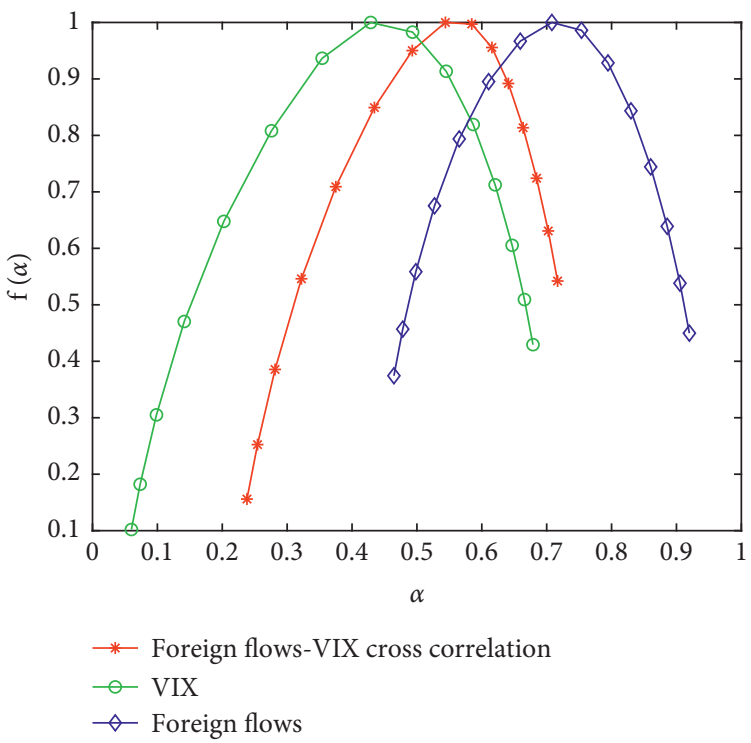

(e)

Figure 7: Cross-correlation analysis and MF-DCCA analysis between HGT and VIX index. (a) Cross-correlation statistics $Q_{c c}(m)$. (b) Log$\log$ plots of $F_{q}(s)$ versus $s$. (c) Generalized Hurst exponent of $H(q)$ versus $q$. (d) Renyi exponent of $\tau(q)$ versus $q$. (e) Multifractal spectrum $f(\alpha)$ versus $\alpha$.

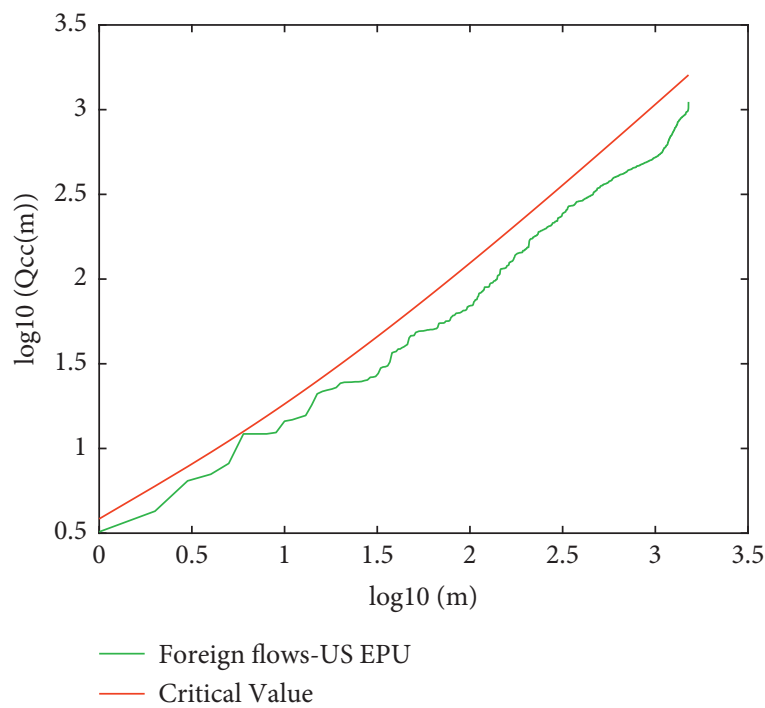

(a)

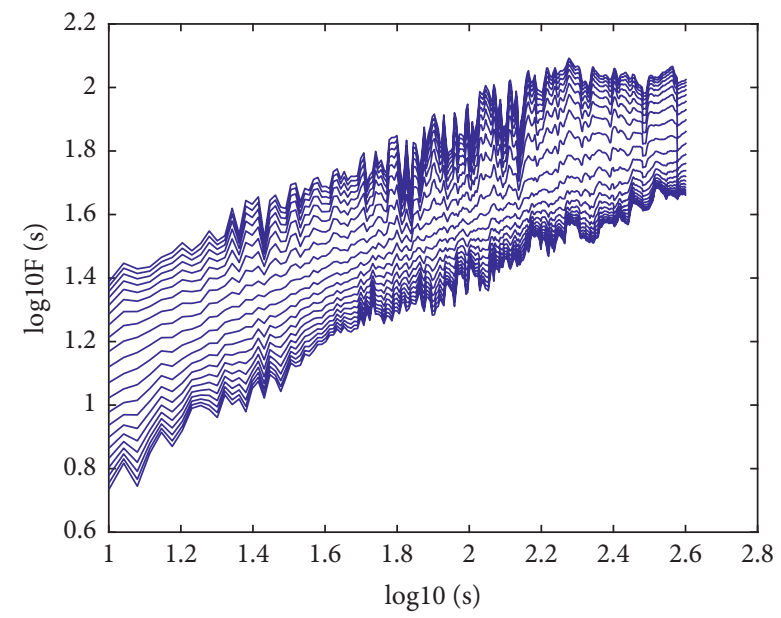

(b)

FIgure 8: Continued. 


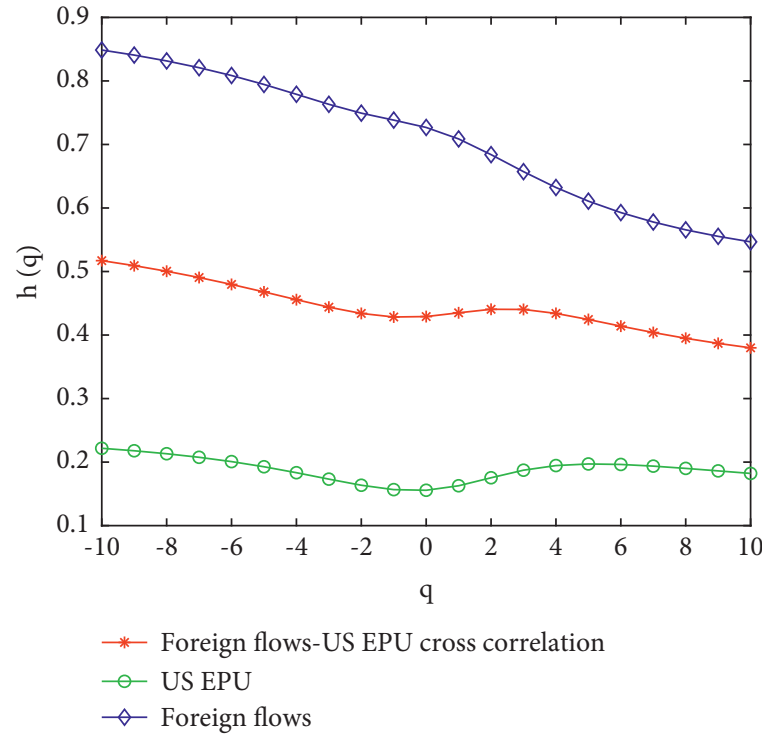

(c)

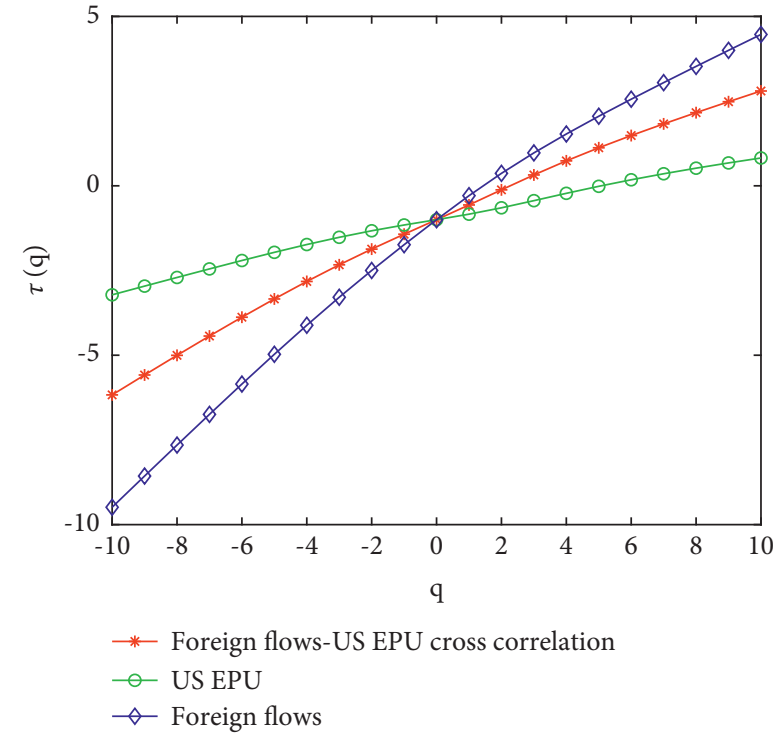

(d)

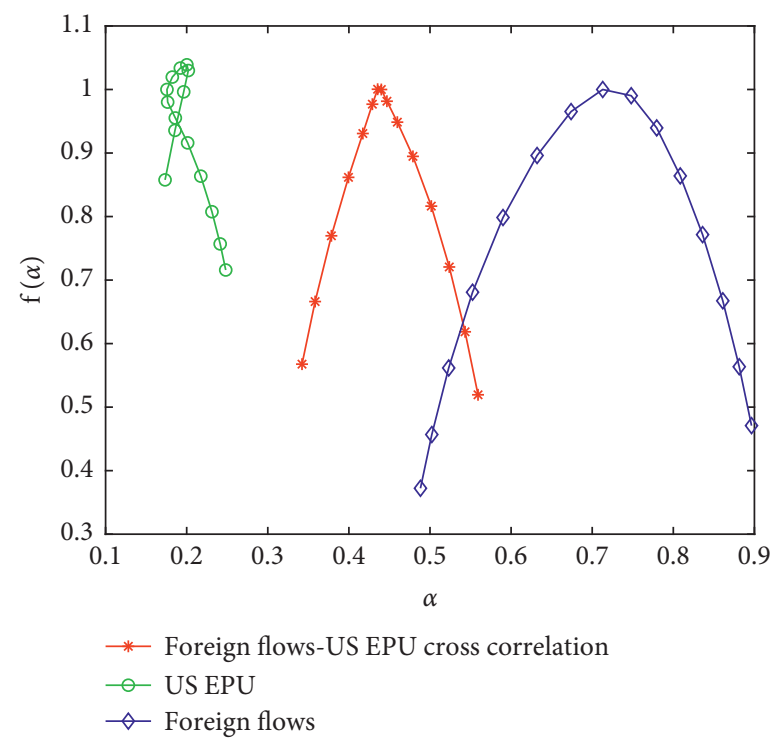

(e)

Figure 8: Cross-correlation analysis and MF-DCCA analysis between HGT and US EPU index. (a) Cross-correlation statistics $Q_{c c}(m)$. (b) Log-log plots of $F_{q}(s)$ versus $s$. (c) Generalized Hurst exponent of $H(q)$ versus $q$. (d) Renyi exponent of $\tau(q)$ versus $q$. (e) Multifractal spectrum $f(\alpha)$ versus $\alpha$.

those for the whole period. After the implementation of Shenzhen-Hong Kong Stock Connect, most values of $H_{x y}(q)$ for foreign flows and VIX are greater than 0.5 (figure (c) in Figures 11 and 12), indicating the positive and persistent cross-correlation. This may be the result of the strong confidence in Chinese economy in recent years, especially the outstanding epidemic prevention and control after the break of COVID-19. And this result is consistent with the foreign investors' significant negative feedback trading during the COVID-19 crisis [14]. 


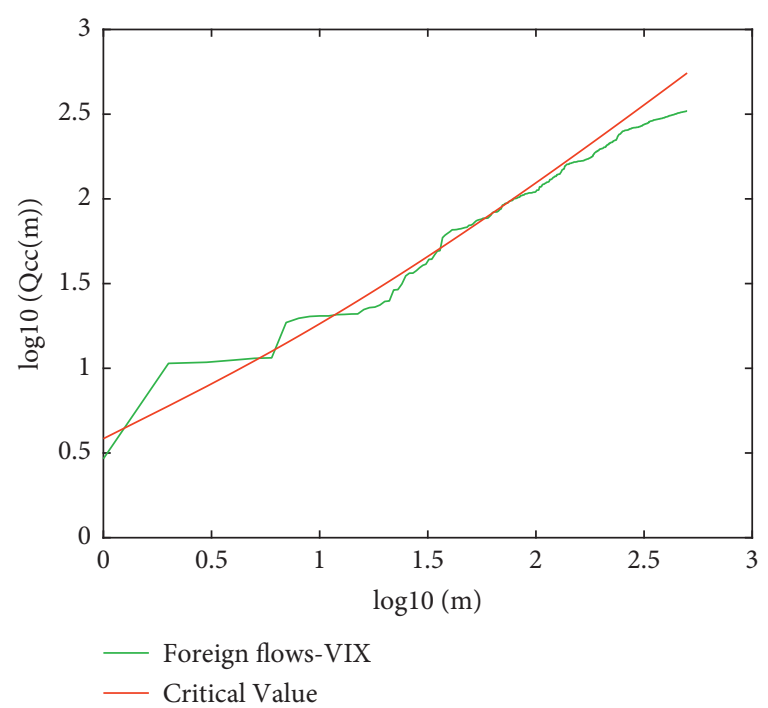

(a)

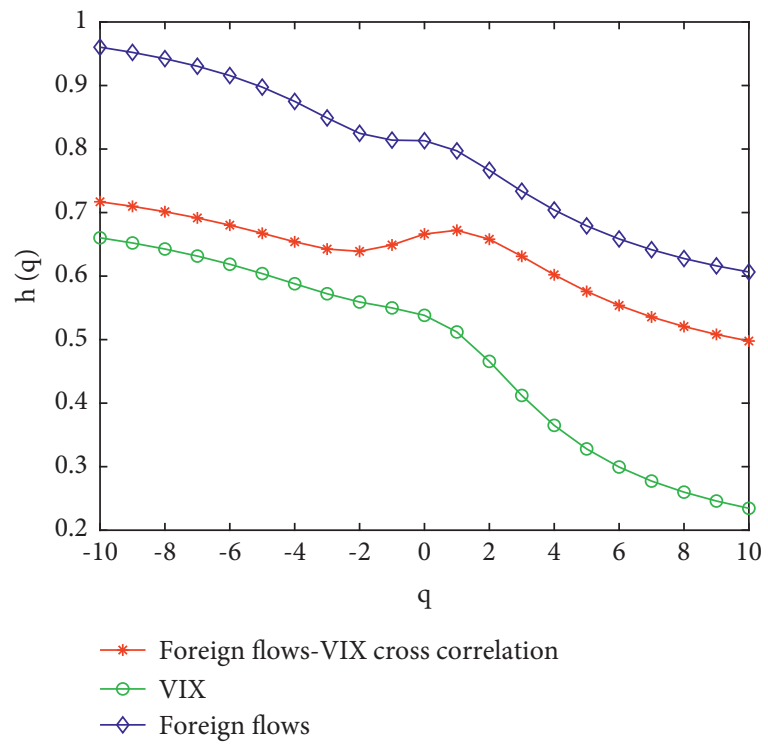

(c)

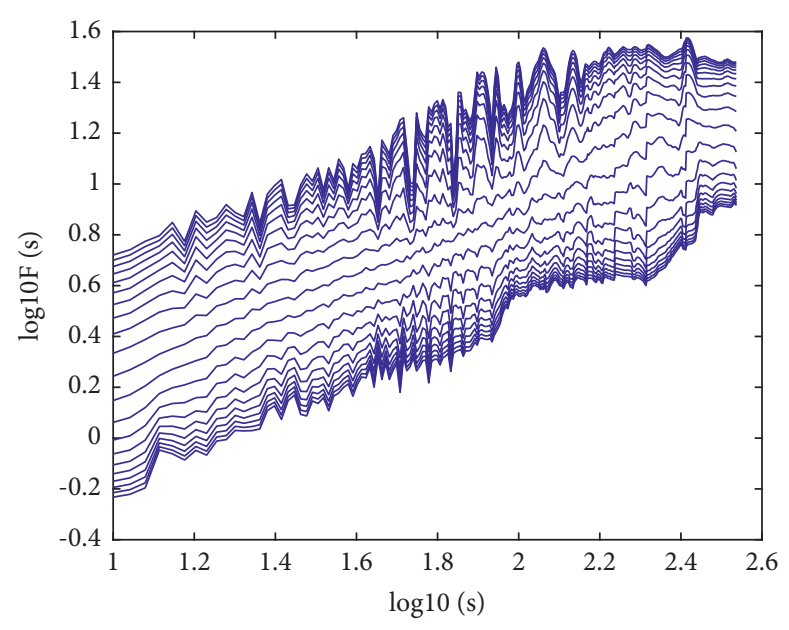

(b)

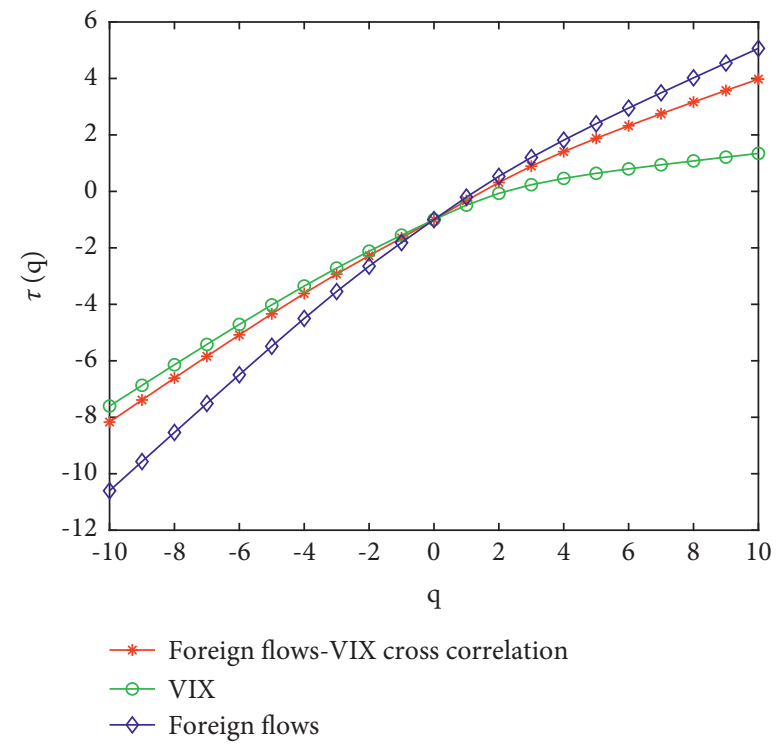

(d)

Figure 9: Continued. 


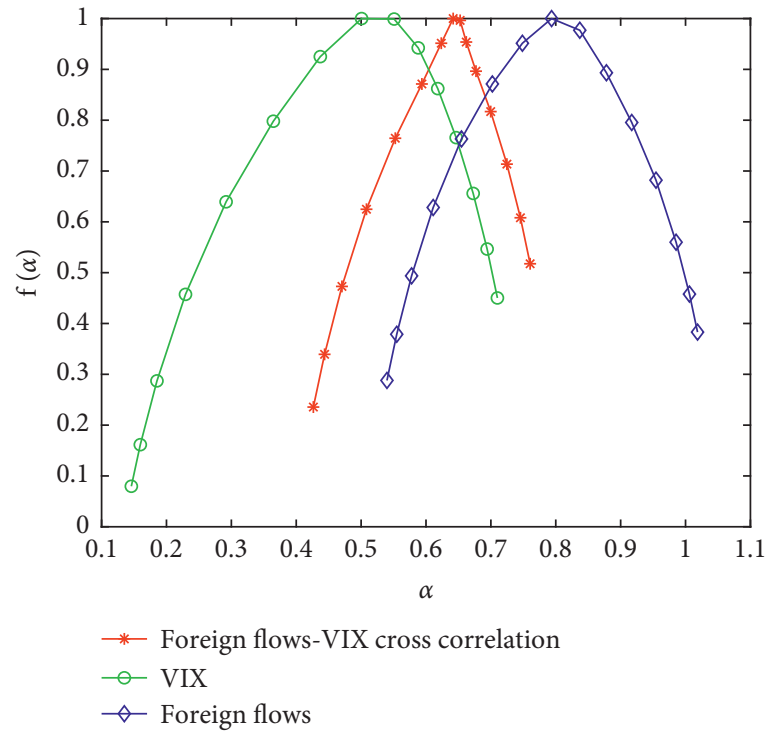

(e)

FIgURE 9: Cross-correlation analysis and MF-DCCA analysis between SGT and VIX index. (a) Cross-correlation statistics $Q_{c c}(m)$. (b) Log$\log$ plots of $F_{q}(s)$ versus $s$. (c) Generalized Hurst exponent of $H(q)$ versus $q$. (d) Renyi exponent of $\tau(q)$ versus $q$. (e) Multifractal spectrum $f(\alpha)$ versus $\alpha$.

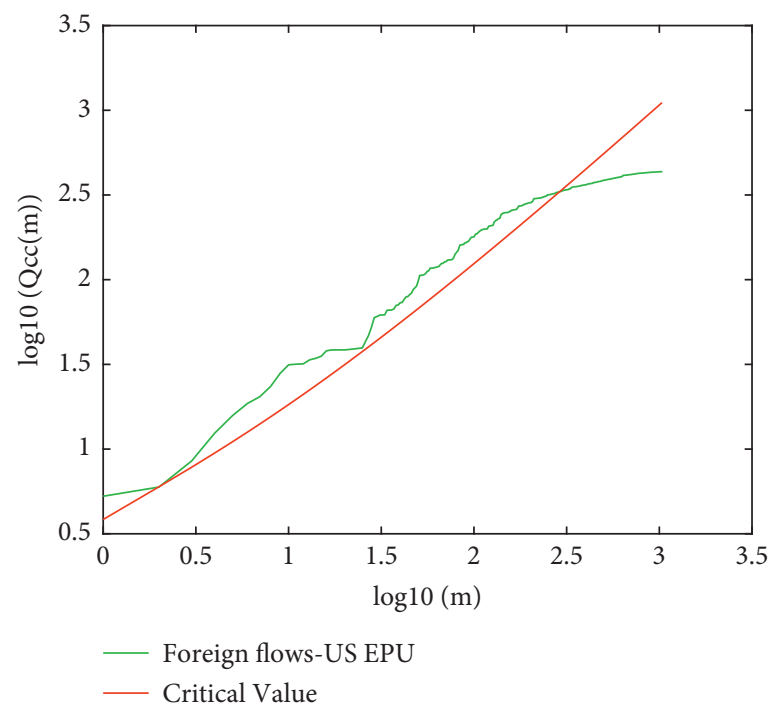

(a)

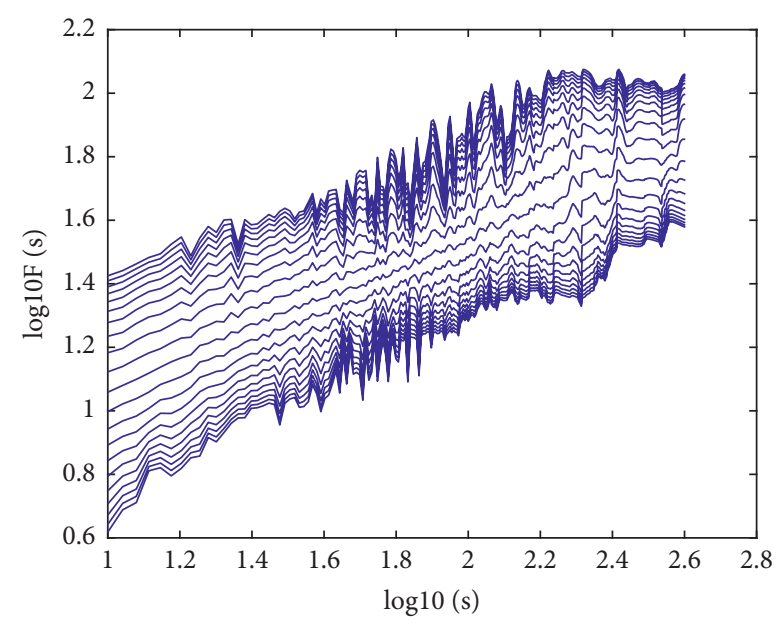

(b)

Figure 10: Continued. 


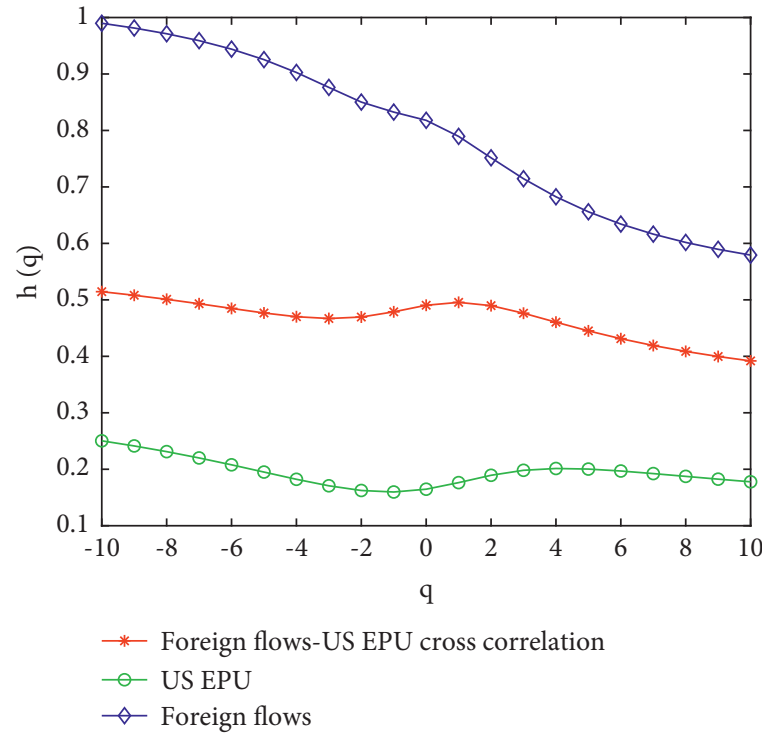

(c)

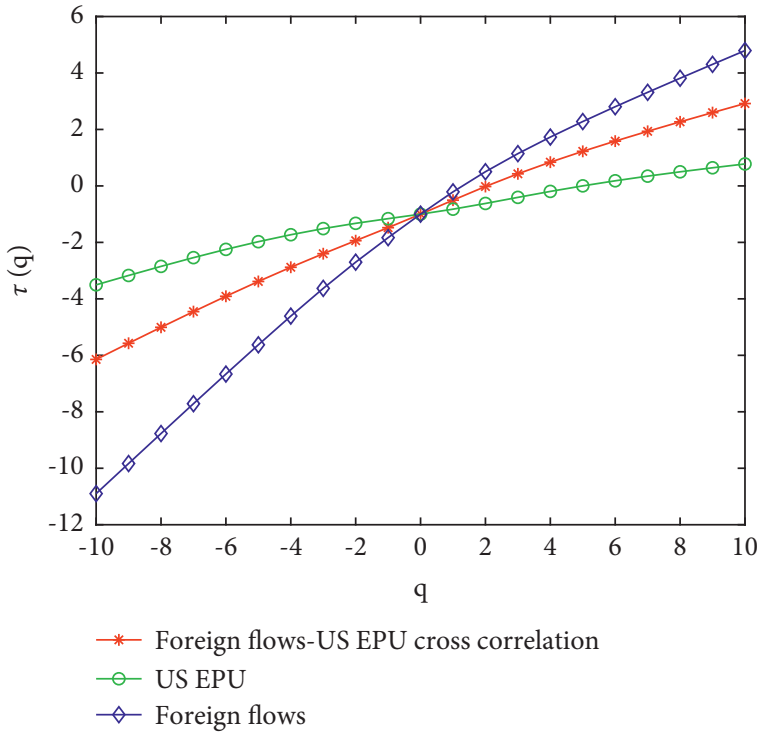

(d)

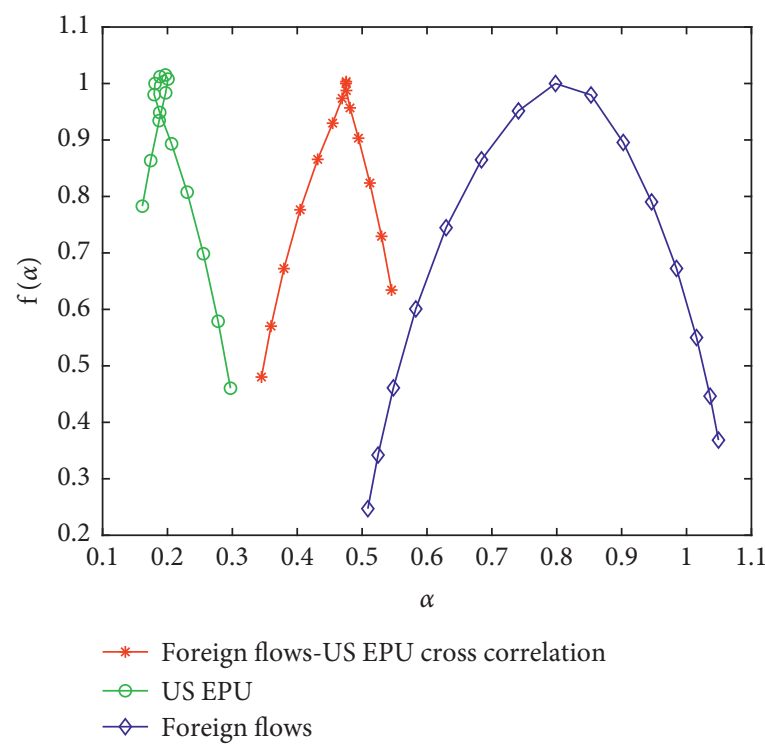

(e)

FIGURE 10: Cross-correlation analysis and MF-DCCA analysis between SGT and US EPU index. (a) Cross-correlation statistics $Q_{c c}(m)$. (b) Log-log plots of $F_{q}(s)$ versus $s$. (c) Generalized Hurst exponent of $H(q)$ versus $q$. (d) Renyi exponent of $\tau(q)$ versus $q$. (e) Multifractal spectrum $f(\alpha)$ versus $\alpha$. 


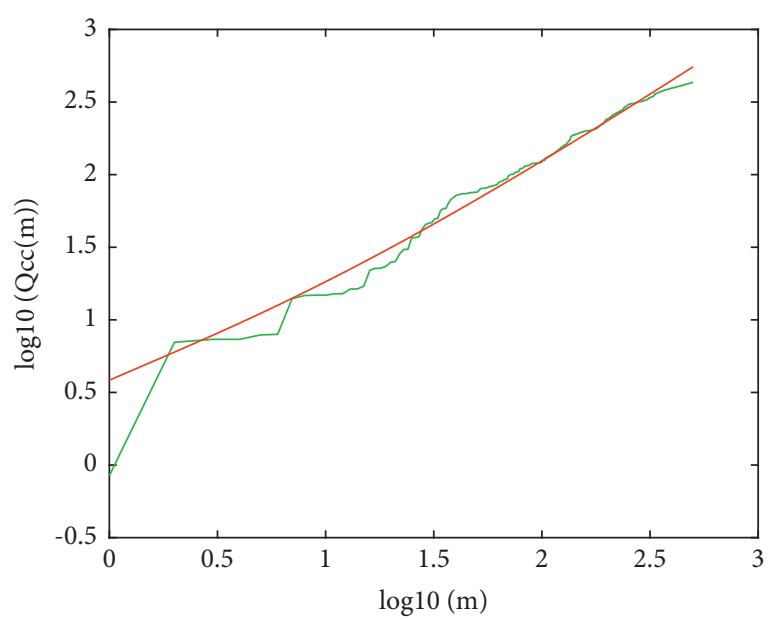

— Foreign flows-VIX

_ Critical Value

(a)

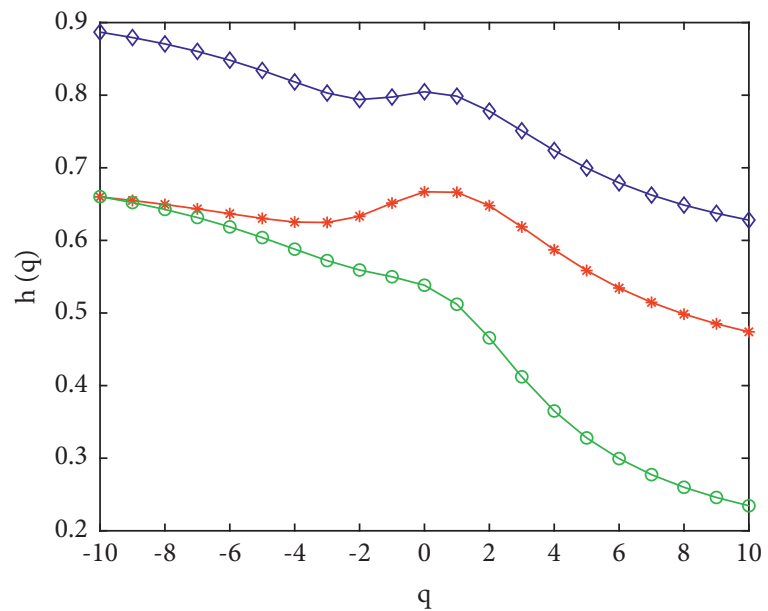

*- Foreign flows-VIX cross correlation

- - VIX

$\diamond$ Foreign flows

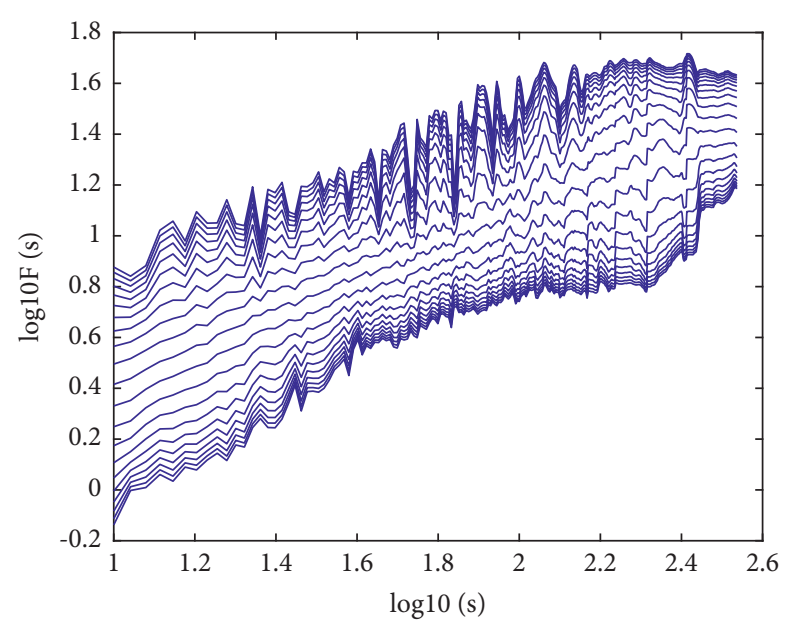

(b)

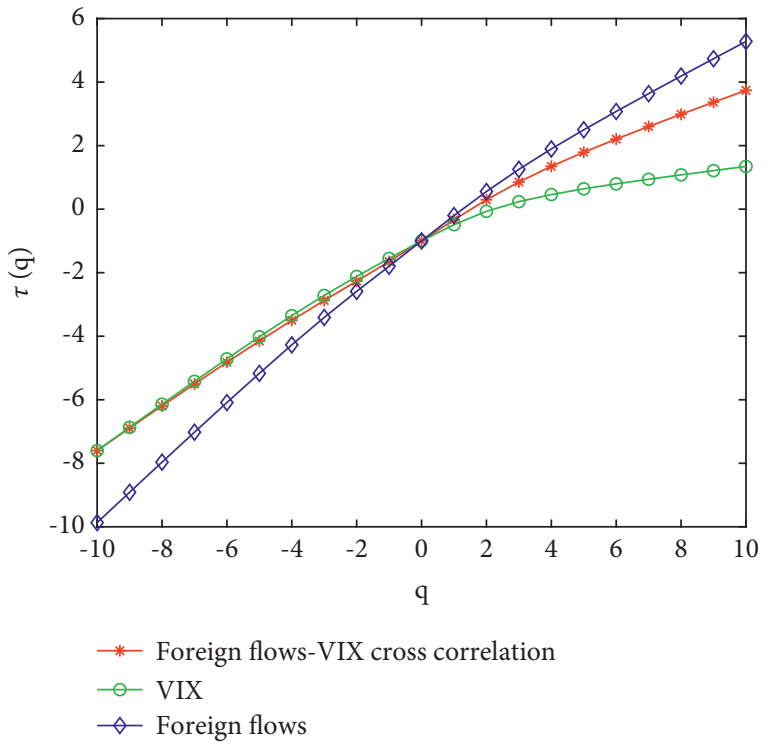

(d)

FIgUre 11: Continued. 


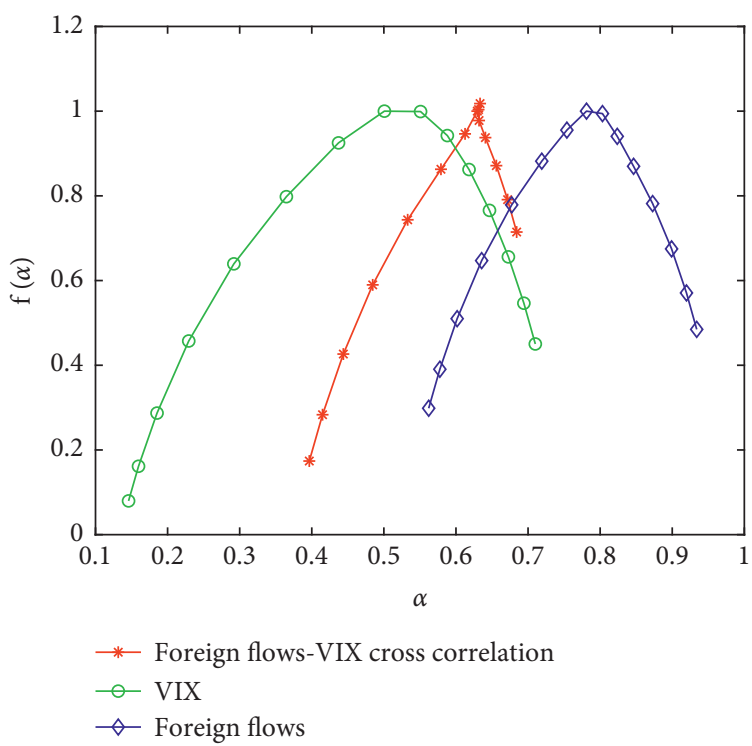

(e)

Figure 11: Cross-correlation analysis and MF-DCCA analysis between the foreign flows after the implementation of Shenzhen-Hong Kong Stock Connect and VIX index. (a) Cross-correlation statistics $Q_{c c}(m)$. (b) Log-log plots of $F_{q}(s)$ versus $s$. (c) Generalized Hurst exponent of $H(q)$ versus $q$. (d) Renyi exponent of $\tau(q)$ versus $q$. (e) Multifractal spectrum $f(\alpha)$ versus $\alpha$.

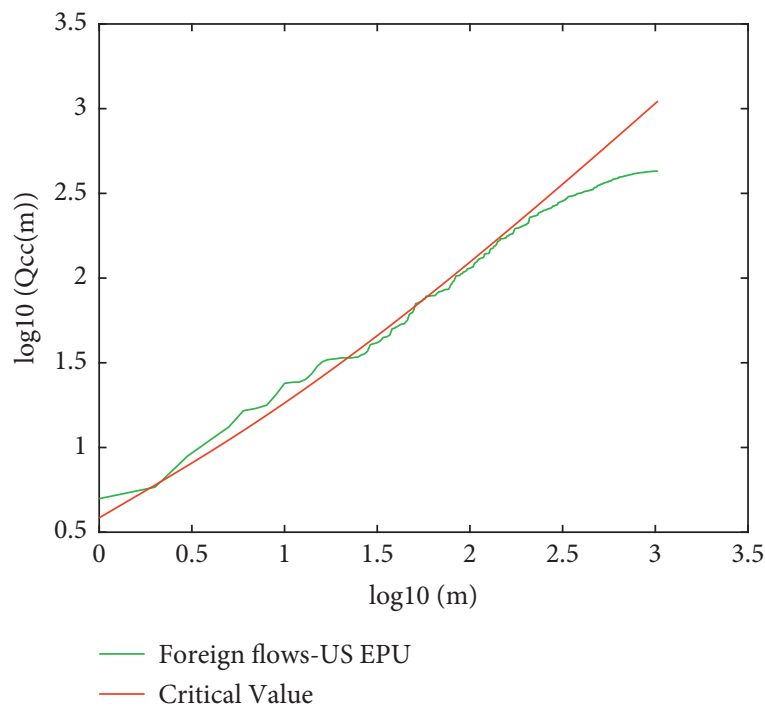

(a)

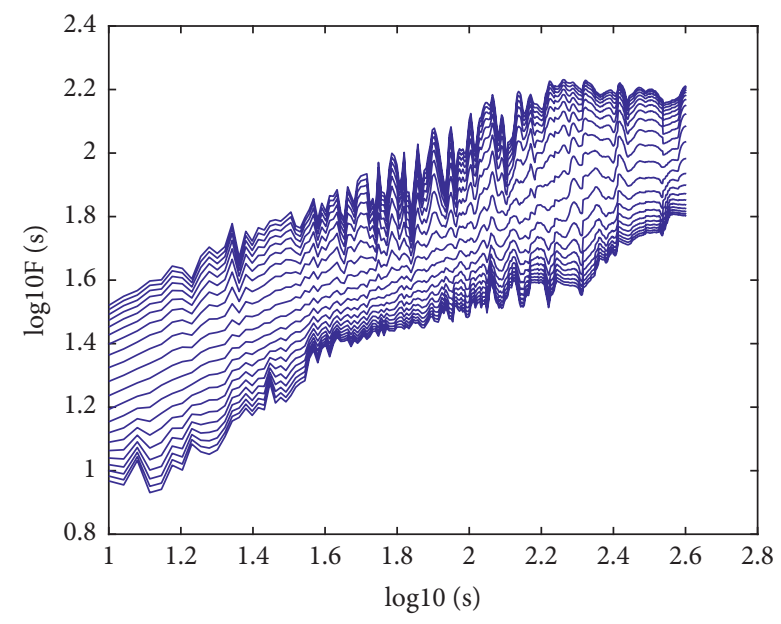

(b)

FIGURE 12: Continued. 


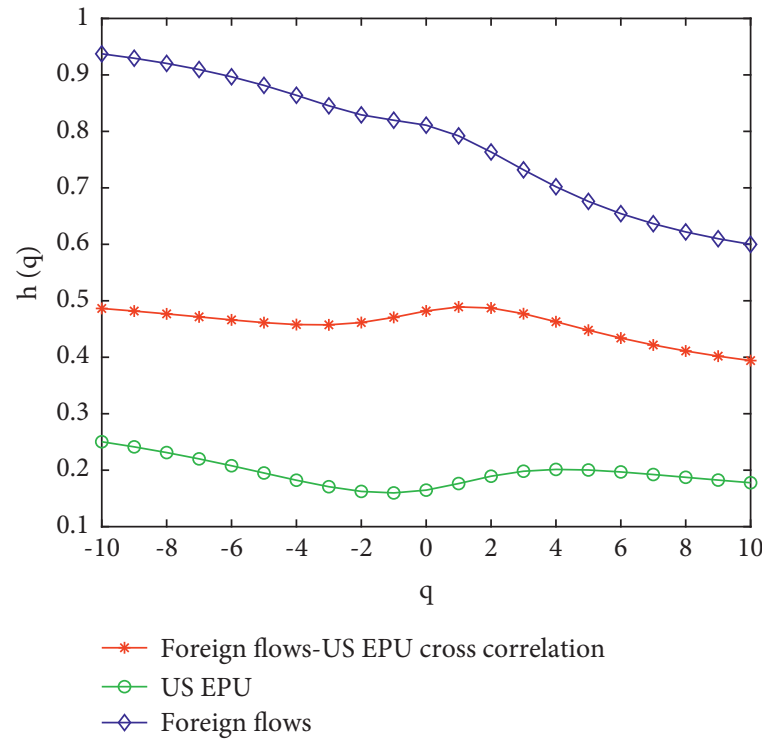

(c)

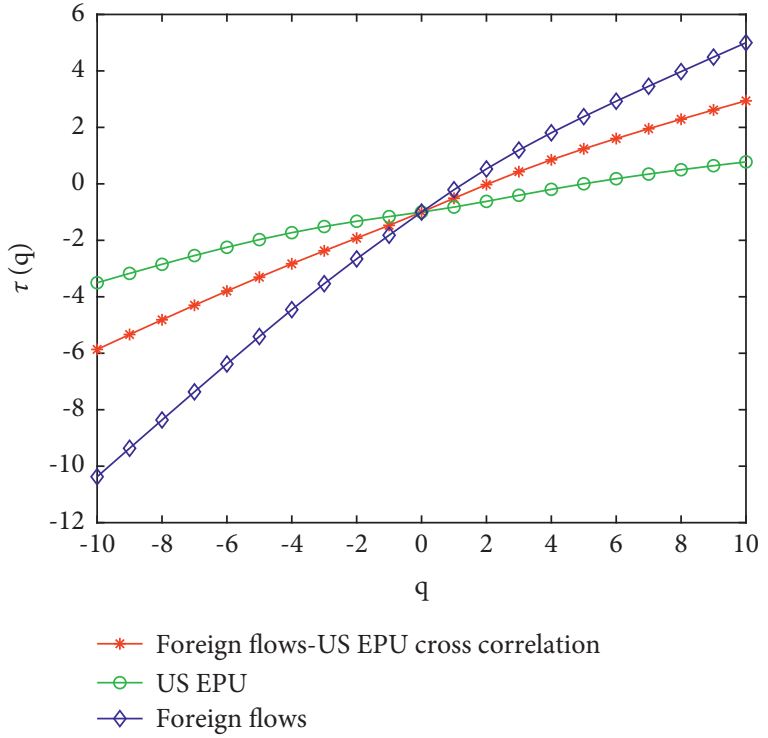

(d)

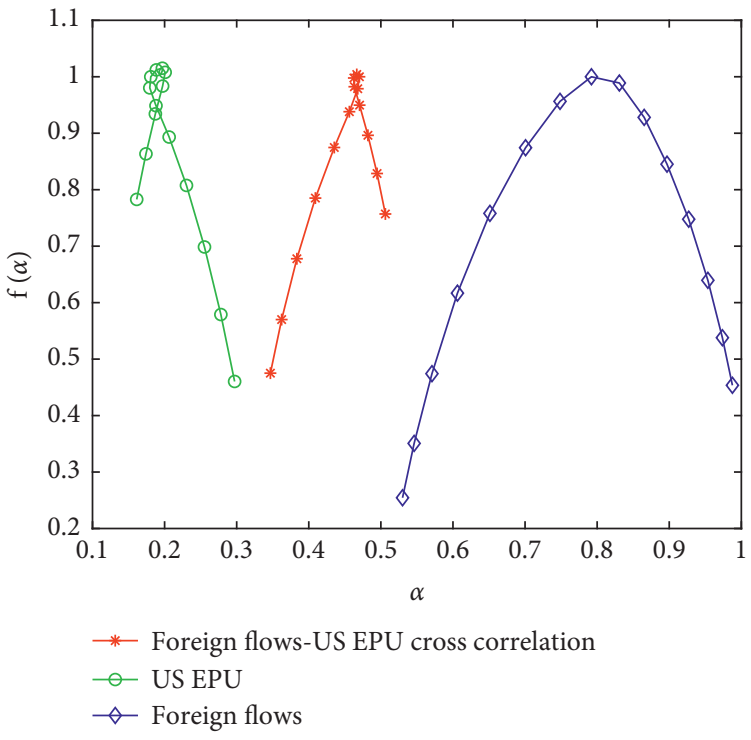

(e)

Figure 12: Cross-correlation analysis and MF-DCCA analysis between the foreign flows after the implementation of Shenzhen-Hong Kong Stock Connect and US EPU index. (a) Cross-correlation statistics $Q_{c c}(m)$. (b) Log-log plots of $F_{q}(s)$ versus $s$. (c) Generalized Hurst exponent of $H(q)$ versus $q$. (d) Renyi exponent of $\tau(q)$ versus $q$. (e) Multifractal spectrum $f(\alpha)$ versus $\alpha$.

\section{Conclusions}

The relationship between the foreign flows in emerging markets and the influence factors in home market has been a main undertaking in international finance and microstructure literature. However, most literatures only explore the linear relationship. Few have focused on the nonlinear relationship. Using the MF-DCCA method, this paper investigates the cross-correlations between the foreign flows in A-share market and the push factors, namely, the uncertainties of market, economy, and policy in the home market, which are measured by the VIX index and the US EPU index, respectively. The cross-correlation statistics qualitatively show the existence of the cross-correlation between the foreign flows and the VIX index and the foreign flows and the US EPU index. Then, the MF-DCCA method confirms their long-term cross-correlation from the quantitative perspective. In addition, the cross-correlation between the foreign flows and VIX is persistent, when the fluctuations are small. However, the cross-correlation is antipersistent, when the fluctuations are large. In contrast, the cross-correlation between the foreign flows and US EPU is antipersistent and steady. Besides, the strength of the cross-correlation between the foreign flows and VIX is larger than that between the 
foreign flows and US EPU. And the results are robust using the separate foreign flows, namely, the flows via ShanghaiHong Kong Stock Connect Program and Shenzhen-Hong Kong Stock Connect Program, and flows with shortening period.

\section{Data Availability}

The data used to support the findings of this study are available from the author upon request.

\section{Conflicts of Interest}

The authors declare that they have no conflicts of interest.

\section{Authors' Contributions}

The authors contributed equally to the writing of this paper. The authors read and approved the final manuscript.

\section{Acknowledgments}

This study was supported by the Fundamental Research Funds from Capital University of Economic and Business (Grant No. XRZ2020041), the National Natural Science Foundation of China (Grant No. 72103210), the Humanity and Social Science Youth Foundation of the Ministry of Education of China (Grant No. 18YJC790115), and the Soft Science Foundation of Science and Technology Department of Guangdong, China (Grant No. 2019A101002019).

\section{References}

[1] G. A. Calvo, L. Leiderman, and C. M. Reinhart, "Capital inflows and real exchange rate appreciation in Latin America: the role of external factors," Staff Papers - International Monetary Fund, vol. 40, no. 1, pp. 108-151, 1993.

[2] E. Fernandez-Arias, "The new wave of private capital inflows: push or pull?" Journal of Development Economics, vol. 48, no. 2, pp. 389-418, 1996.

[3] M. P. Taylor and L. Sarno, "Capital flows to developing countries: long- and short-term determinants," The World Bank Economic Review, vol. 11, no. 3, pp. 451-470, 1997.

[4] P.-R. Agénor, "The surge in capital flows: analysis of "pull" and "push" factors," International Journal of Finance \& Economics, vol. 3, no. 1, pp. 39-57, 1998.

[5] P. Chuhan, S. Claessens, and N. Mamingi, "Equity and bond flows to Latin America and Asia: the role of global and country factors," Journal of Development Economics, vol. 55, no. 2, pp. 439-463, 1998.

[6] K. J. Forbes and F. E. Warnock, "Capital flow waves: surges, stops, flight, and retrenchment," Journal of International Economics, vol. 88, no. 2, pp. 235-251, 2012.

[7] M. Fratzscher, "Capital flows, push versus pull factors and the global financial crisis," Journal of International Economics, vol. 88, no. 2, pp. 341-356, 2012.

[8] A.-M. Fuertes, K. Phylaktis, and C. Yan, "Hot money in bank credit flows to emerging markets during the banking globalization era," Journal of International Money and Finance, vol. 60, pp. 29-52, 2016.
[9] R. Koepke, "What drives capital flows to emerging markets? A survey of the empirical literature," Journal of Economic Surveys, vol. 33, no. 2, pp. 516-540, 2019.

[10] E. Borensztein and R. G. Gelos, "A panic-prone pack? The behavior of emerging market mutual funds," IMF Staff Papers, vol. 50, no. 1, pp. 43-63, 2003.

[11] T. Omay and P. Iren, "Behavior of foreign investors in the Malaysian stock market in times of crisis: a nonlinear approach," Journal of Asian Economics, vol. 60, pp. 85-100, 2019.

[12] M. Hood, A. Kamesaka, J. Nofsinger, and T. Tamura, "Investor response to a natural disaster: evidence from Japan's 2011 earthquake," Pacific-Basin Finance Journal, vol. 25, pp. 240-252, 2013.

[13] J. R. Gerlach and Y. Yook, "Political conflict and foreign portfolio investment: evidence from North Korean attacks," Pacific-Basin Finance Journal, vol. 39, pp. 178-196, 2016.

[14] T. Bing and H. Ma, "COVID-19 pandemic effect on trading and returns: evidence from the Chinese stock market," Economic Analysis and Policy, vol. 71, pp. 384-396, 2021.

[15] H. Choe, B. C. Kho, and R. M. Stulz, "Do foreign investors destabilize stock markets? The Korean experience in 1997," Journal of Financial Economics, vol. 54, no. 2, pp. 227-264, 1999.

[16] M. Bowe and D. Domuta, "Investor herding during financial crisis: a clinical study of the Jakarta Stock Exchange," PacificBasin Finance Journal, vol. 12, no. 4, pp. 387-418, 2004.

[17] Z.-Q. Jiang, W.-J. Xie, W.-X. Zhou, and D. Sornette, "Multifractal analysis of financial markets: a review," Reports on Progress in Physics, vol. 82, no. 12, p. 125901, 2019.

[18] P.-F. Dai, X. Xiong, and W.-X. Zhou, "Visibility graph analysis of economy policy uncertainty indices," Physica A: Statistical Mechanics and Its Applications, vol. 531, p. 121748, 2019.

[19] R. Zhao and P.-F. Dai, "A multifractal cross-correlation analysis of economic policy uncertainty: evidence from China and US," Fluctuation and Noise Letters, vol. 20, no. 5, p. 2150041, 2021.

[20] W. X. Zhou, "Multifractal detrended cross-correlation analysis for two nonstationary signals," Physical review. E, Statistical, nonlinear, and soft matter physics, vol. 77, no. 6, p. 066211, 2008.

[21] W. Zhang, Y. Li, Z. Zhang, and D. Shen, "The dynamic crosscorrelations between foreign news, local news and stock returns," Physica A: Statistical Mechanics and Its Applications, vol. 509, pp. 861-872, 2018.

[22] Z. Zhang, Y. Zhang, D. Shen, and W. Zhang, "The dynamic cross-correlations between mass media news, new media news, and stock returns," Complexity, vol. 2018, Article ID 7619494, 11 pages, 2018.

[23] Z. Zhang, Y. Zhang, and D. Shen, "The dynamic correlations between mass media news and new media news in stock market," Frontiers in Physics, vol. 8, p. 179, 2020.

[24] K. Xu, Y. Pang, and J. Han, "Dynamic cross-correlation between online sentiment and stock market performance: a global view," Discrete Dynamics in Nature and Society, vol. 2021, Article ID 6674379, 11 pages, 2021.

[25] R. Zhao and Y. Cui, "Dynamic cross-correlations analysis on economic policy uncertainty and US dollar exchange rate: AMF-DCCA perspective," Discrete Dynamics in Nature and Society, vol. 2021, Article ID 6668912, 9 pages, 2021.

[26] S. Li, X. Lu, and X. Liu, "Dynamic relationship between Chinese RMB exchange rate index and market anxiety: a new perspective based on MF-DCCA," Physica A: Statistical Mechanics and its Applications, vol. 541, p. 123405, 2020. 
[27] S. Ye, P.-F. Dai, H. T. Nguyen, and N. Q. A. Huynh, "Is the cross-correlation of EU carbon market price with policy uncertainty really being? A multiscale multifractal perspective," Journal of Environmental Management, vol. 298, p. 113490, 2021.

[28] M. Foglia and P. F. Dai, “"Ubiquitous uncertainties”: spillovers across economic policy uncertainty and cryptocurrency uncertainty indices," Journal of Asian Business and Economic Studies, 2021.

[29] X. Xiong, K. Xu, and D. Shen, "Dynamic cross-correlations between investors' attention and CSI300 index futures," Fluctuation and Noise Letters, vol. 18, no. 4, p. 1950022, 2019.

[30] W. Zhang, P. Wang, X. Li, and D. Shen, "Multifractal detrended cross-correlation analysis of the return-volume relationship of bitcoin market," Complexity, vol. 2018, Article ID 8691420, 20 pages, 2018.

[31] W. Zhang, P. Wang, X. Li, and D. Shen, "Quantifying the cross-correlations between online searches and Bitcoin market," Physica A: Statistical Mechanics and its Applications, vol. 509, pp. 657-672, 2018.

[32] Z. Zhang, Y. Zhang, D. Shen, and W. Zhang, "The crosscorrelations between online sentiment proxies: evidence from Google Trends and Twitter," Physica A: Statistical Mechanics and its Applications, vol. 508, pp. 67-75, 2018.

[33] G. Sarwar, "Is VIX an investor fear gauge in BRIC equity markets?" Journal of Multinational Financial Management, vol. 22, no. 3, pp. 55-65, 2012.

[34] S. R. Baker, N. Bloom, and S. J. Davis, "Measuring economic policy uncertainty*," Quarterly Journal of Economics, vol. 131, no. 4, pp. 1593-1636, 2016.

[35] B. Podobnik and H. E. Stanley, "Detrended cross-correlation analysis: a new method for analyzing two nonstationary time series," Physical Review Letters, vol. 100, no. 8, p. 084102, 2008.

[36] S. Shadkhoo and G. R. Jafari, "Multifractal detrended crosscorrelation analysis of temporal and spatial seismic data," The European Physical Journal B, vol. 72, no. 4, pp. 679-683, 2009.

[37] Y. Yuan, X.-T. Zhuang, and X. Jin, "Measuring multifractality of stock price fluctuation using multifractal detrended fluctuation analysis," Physica A: Statistical Mechanics and Its Applications, vol. 388, no. 11, pp. 2189-2197, 2009.

[38] M. Arak and N. Mijid, "The VIX and VXN volatility measures: fear gauges or forecasts?" Derivatives Use, Trading and Regulation, vol. 12, no. 1, pp. 14-27, 2006.

[39] M. M. Copeland and T. E. Copeland, "Market timing: style and size rotation using the VIX," Financial Analysts Journal, vol. 55, no. 2, pp. 73-81, 1999.

[40] R. E. Whaley, "Understanding the VIX," Journal of Portfolio Management, vol. 35, no. 3, pp. 98-105, 2009.

[41] R. E. Whaley, "The investor fear gauge," Journal of Portfolio Management, vol. 26, no. 3, pp. 12-17, 2000.

[42] B. Julio and Y. Yook, "Political uncertainty and corporate investment cycles," The Journal of Finance, vol. 67, no. 1, pp. 45-83, 2012.

[43] Y. Sha, C. Kang, and Z. Wang, "Economic policy uncertainty and mergers and acquisitions: evidence from China," Economic Modelling, vol. 89, pp. 590-600, 2020.

[44] S. A. Al-Thaqeb and B. G. Algharabali, "Economic policy uncertainty: a literature review," The Journal of Economic Asymmetries, vol. 20, p. e00133, 2019.
[45] P.-F. Dai, X. Xiong, and W.-X. Zhou, "A global economic policy uncertainty index from principal component analysis," Finance Research Letters, vol. 40, p. 101686, 2021.

[46] P. F. Dai, X. Xiong, and W. X. Zhou, "The role of global economic policy uncertainty in predicting crude oil futures volatility: evidence from a two-factor GARCH-MIDAS model," 2020, https://arxiv.org/abs/2007.12838. 